\title{
Las rentas del ducado de Feria en la segunda mitad del siglo XVIII
}

\author{
Manuel Sanchez Gómez-Coronado
}

El ducado de Feria, situado al suroeste de Extremadura, era a mediados del siglo xviı uno de los estados del duque de Medinaceli y representaba una parte de las posesiones de la Casa señorial ". Estaba formado por dos espacios de diferentes características:

Este arículo es una sintesis de la primera parte del Capitulo VI de nuestra tesis doctoral que, bajo el título: La crisis del Régimen Señorial en el ducado de Feria a final de la Edad Moderna, defenderemos en la Facultad de Geografía e Historia de la Universidad Nacional de Educación a Distancia dentro de breve plazo de tiempo.

En relación a la renta señorial se han realizado magníficos trabajos de investigación, que nos han servido de guía: Grupo 73, La economia del Antiguo Régimen, el Señorio de Buitrago. Madrid 1973; Estepa GIMÉnEZ, J., Aportación al estudio de la disolución del régimen señorial. Puente Genil, 1750-1850. Puente Genil 1980; El Marquesado de Priego en la disolución del régimen señorial andaluz. Córdoba 1987; Contreras, J., «Las formas de explotación en la Andalucía del siglo xvIII: los estados de Osuna», en La economía agraria en la Historia de España. Madrid 1979; Garcia SAnz, A., "Renta y sociedad estamental en el Marquesado de Cuéllar, en Estudios Segovianos, n. ${ }^{\circ} 74-75,1973$; Desarrollo y crisis del Antiguo Régimen en Castilla la Vieja. Madrid 1977; GuILARTE, A. M., El régimen señorial en el siglo xvi. Madrid 1962; Atienza Hernández, I., Aristocracia, poder y riqueza en la España Moderna. La Casa de Osuna, siglos xv-xix. Madrid 1987; Morant Deusa, I., El declive del señorio. Los dominios del ducado de Gandia, 1705-1837. Valencia 1984 Ruiz Torres, P., Señores y propietarios. Cambio social en el sur valenciano, 1650-1850. Valencia 1981; CoLAS LAtorre, G., La bailia de Caspe en los siglos xvı y xvIl. Zaragoza 1987; GIL OlCINA, A., La propiedad señorial en tierras valencianas. Valencia 1979; SALOMON, N., La vida rural castellana en tiempos de Felipe II. Barcelona 1973; VILLARES, R., La propiedad de la tierra en Galicia, 1500-1936. Madrid 1982; López-SalazAR PÉFEz, J., Estructuras agrarias y sociedad rural en la Mancha (siglos xvi-xvil). Ciudad Real 1986.

$\mathrm{Ha}$ habido algunas aproximaciones al tema de las rentas del Estado de Feria en la Época Moderna. Un articulo de JAGO, $C H$., "La crisis de la aristocracia en la Castilla del siglo xVIl»; en Poder y sociedad en la España de los Austrias. Barcelona 1982, págs. 248-286; GaRDALLIAGUET M. ha aludido a ello brevemente en dos artículos: "Las rentas señoriales del ducado de Feria a finales del Antiguo Régimen", en Actas de las II jornadas de Metodologia y Didáctica de la Historia. Cáceres 1983, págs. 177-190, y «Zafra y su comarca a finales del Antiguo Régimen», Revista de Estudios Extremeños, t. XL, n. ${ }^{\circ}$ III, 1984, págs. 527-564; mientras que Aragón Mateos, S., en su magnífico estudio: La nobleza extremeña en el siglo Xvil. Mérida 1990, hace atinados comentarios sobre la cuestión. 
- Las villas en las que el duque ejercía un señorío meramente jurisdiccional, constituido por Zafra, Feria, La Parra, Alconera, Torre de Miguel Sexmero, Almendral, La Morera y Salvatierra. Fueron adquiridas como consecuencia de donaciones reales en el período bajo medieval, excepto Salvatierra que se compró en el siglo xvi.

- Un grupo de villas en las que detentaba el señorío pleno o mixto, de las que formaban parte Oliva de la Frontera, Valencia del Mombuey, Nogales, Salvaleón y el marquesado de Villalba, en el que además de ésta se formaron otros tres núcleos de población: Santa Marta, Solana y Corte de Peleas.

El duque desde Madrid, y a través de una Secretaría y una Contaduría Mayor, gobernaba y administraba sus diferentes estados ubicados en Castilla, Andalucía, Extremadura, Valencia y Cataluña. Para el ducado de Feria tenia establecido un entramado administrativo en Zafra, como capital del señorio, formado por la Contaduria General, a cuyo frente estaba el contador, que realizaba la tarea de apoderado, administrador y defensor de todos los derechos económicos, señoriales y de patronazgo, ayudado por el oficial mayor, el oficial segundo, el oficial agregado y el portero ${ }^{2}$.

Desde la contaduria se administraban directamente las rentas ducales en Feria, La Parra, La Morera, Salvaleón, La Torre de Miguel Sexmero, Almendral, Alconera y Salvatierra, pues en estos pueblos gravitaban casi de manera exclusiva sobre las alcabalas. En la mayoría de los casos las arrendaban los ayuntamientos de los pueblos, mediante el pago al Duque de una cantidad fija anual. Las dehesas ubicadas en estas villas y las de los despoblados de Bejarana y Palacio se arrendaban en muchas ocasiones por la contaduria de Madrid, y otras veces por la de Zafra. Para vigilar la conservación del arbolado y las cláusulas del arrendamiento, el Duque nombraba un guarda en las dehesas de Palacio, Bejarana, Salamanco, Santa Justa, Monturque, Matilla y Marihernández, Rincón de Almorchón y Redrojo.

La contaduría se complementaba con otras entidades recaudatorias. En Zafra se ubicaba una administración de alcabalas dirigida por un ad-

Conocemos el funcionamiento y la actuación de la contaduria general de Zafra gracias a dos documentos de gran interés, que incluyen instrucciones muy precisas para las tareas a desempeñar por esta oficina: Archivo Histórico Municipal de Zafra (AHMZ), Fondo Documental del ducado de Feria (FDF), Carp. 118, leg. 9. Instrucción para la Administración de las rentas del ducado, 1741; y Carp. 147, leg. 1. Adiciones a los capítulos de la instrucción de esa contaduria, 1773. 
Las rentas del ducado de Feria en la segunda mitad del siglo xvm

ministrador, al que ayudaban un guarda mayor y varios guardas ordinarios que se situaban en las puertas de la población y exigían a los vendedores la exhibición de la papeleta de pago. El fiel de la romana les controlaba lo que vendía cada uno. El fiel del Almotacén entregaba pesos, varas y medidas a todo comerciante que lo necesitaba, cobrando por ello unos derechos.

En otras villas del Estado existian varias mayordomías, oficinas administrativas que dependian de la contaduria y tenian la misión de recaudar las rentas y derechos ducales. En la primera mitad del siglo xvIli habia creadas cinco mayordomias en Oliva, Santa Marta, Nogales, Villalba y Solana. Cada una de ellas contaba con un mayordomo, auxiliado por dos montoneros en el caso de Santa Marta, Nogales y Villalba, y por uno en Oliva y Solana. Probablemente, era excesivo personal para la gestión de las rentas ducales, y por ello se realizó una reforma administrativa a comienzos de los años sesenta del siglo XVIII, cuya consecuencia fue la supresión de las mayordomias de Nogales y Solana, quedando solamente las de Oliva de la Frontera, Santa Marta y Villalba ${ }^{3}$.

A partir de estos momentos la mayordomía de Oliva se encargaba de administrar las rentas del Duque en esta villa y en la de Valencia del Mombuey. La dirigia un mayordomo, que llevaba la contabilidad y rendía un estado de cuentas anual al contador de Zafra, auxiliado por dos montoneros, uno en cada pueblo, que recaudaban los diezmos de grano y le presentaban un estado de lo almacenado. La mayordomía de Santa Marta administraba los bienes de esta villa y de las de Nogales y Corte de Peleas, con la ayuda de los montoneros de Santa Marta y Nogales. La de Villalba se encargaba de esta villa y de Solana y contaba con un montonero en cada una de ellas ${ }^{4}$. A cada mayordomo se le proporcionaba una vivienda en el mismo edificio de mayordomia.

\footnotetext{
${ }^{3}$ La reforma administrativa fue una medida muy frecuente en los señoríos en el siglo Xvill, P. Ruiz Torres se refiere a la efectuada en los señorios valencianos de la Casa de Arcos en 1751, cumpliendo el deseo del Duque de centralizar la percepción de la renta señorial y someterla a un riguroso control y a una vigilancia constante. Se suprimió el cargo de Contador General y se crearon administraciones locales en cada señorio, obligadas a rendir cuentas periódicamente de sus ingresos y gastos a la administración central. Ruíz Torres to interpreta como un intento desesperado por detener la crisis del régimen señorial. Ruiz Torres, P., Señores y propietarios. Cambio social en el sur del Pais Valenciano: 16501850. Valencia 1981, págs. 275-276.

${ }^{4}$ Además de estas mayordomias, la contaduria de Zafra tenía a su cargo la supervisión de la administración del hospital de Santiago ubicado en esa población. El Duque nombraba al mayordomo de la institución hospitalaria que debía rendir cuentas anualmente ante el contador. Sanchez Gómez-Coronado, M. El hospital de Santiago de Zafra en la transición del Antiguo al Nuevo Régimen. Mérida 1987.
} 
El contador enviaba anualmente al Duque una cuenta general de ingresos y gastos de todo el Estado de Feria, por duplicado. Uno de los ejemplares era devuelto a Zafra, firmado y visado por la contaduría mayor, organismo encargado de administrar y supervisar todas sus posesiones. Las cuentas generales estaban organizadas en dos partidas: cargo y data. En el cargo se hacian constar todos los ingresos realizados a lo largo del año en la contaduría por los diferentes mayordomos de las villas, por los arrendadores de las dehesas, de las alcabalas, etc., incluso los no percibidos explicando: «Se ha debido cobrar...». En la primera anotación del cargo se insertaba el alcance de la cuenta anterior, que se sumaba si era positivo, y se restaba si había sido negativo; en segundo lugar se incluian los débitos al duque de años precedentes. En la data se anotaban los gastos, es decir el pago de los empleados, los réditos de los censos, las reparaciones de edificios, los dineros para pleitos e incluso las partidas en efectivo enviadas al Duque. Igualmente, se anotaban como data los débitos que quedaban por cobrar a fin de diciembre de ese año.

\section{EL ESTADO DE FERIA A FINAL DEL ANTIGUO RÉGIMEN}

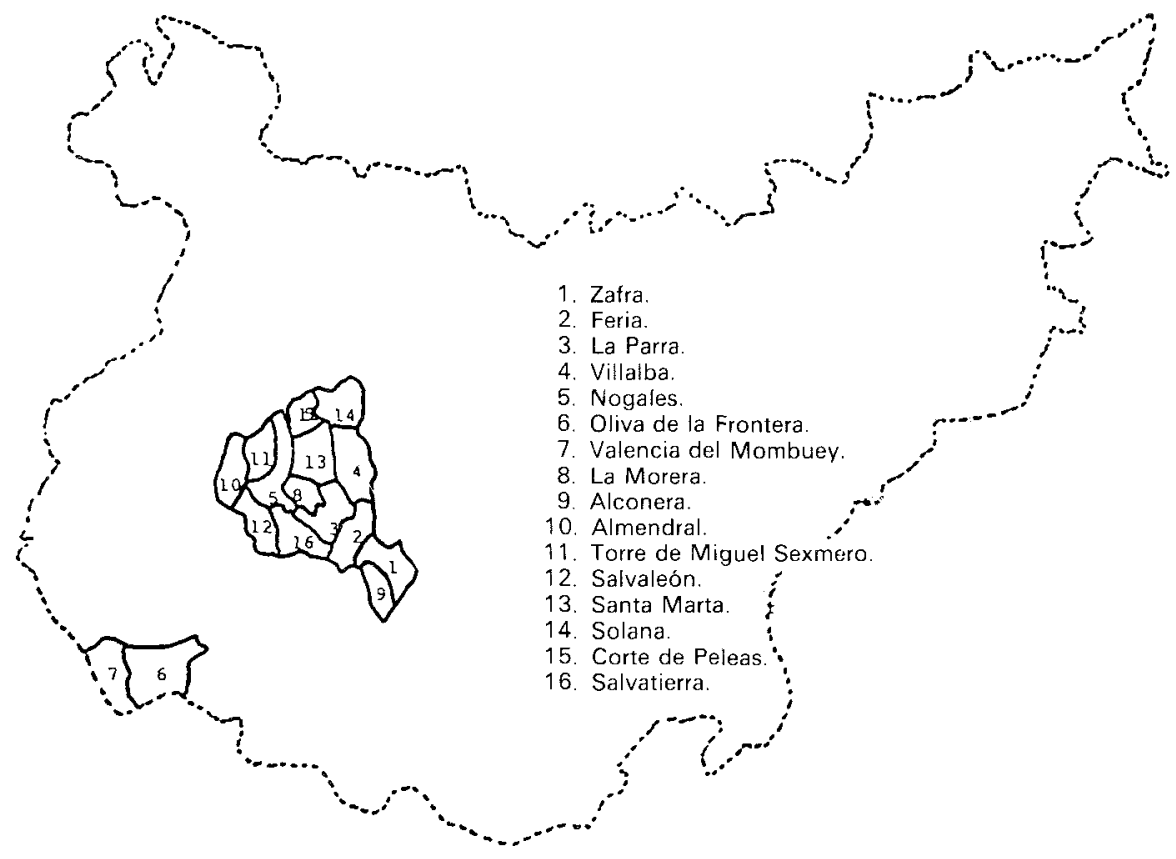




\section{LAS RENTAS DEL DUCADO DE FERIA}

El Estado de Feria se vio, durante el siglo xvIl, en la misma situación de dificultades económicas que eran comunes a toda la nobleza española. Charles Jago ${ }^{5}$ se refiere al comportamiento de las rentas de dicho señorío durante esa centuria y afirma que se produjo una merma en los ingresos pues mientras en el período 1623-1635 crecieron en más del 7 por 100, luego, en el período 1635-1641, se hundieron al disminuir en un 44 por 100. Las dehesas fueron las que resultaron más afectadas al descender en más de un 76 por 100 y las alcabalas en un 30 por 100. La década de 1640 ocasionó un hundimiento financiero casi total que sólo comenzó a recuperarse a partir de 1670 . Jago da algunas de las claves de este desastre al referirse a las consecuencias de la guerra con Portugal, pues los pueblos de Oliva y Valencia del Mombuey fueron devastados por tropas merodeadoras y no proporcionaron rendimientos a la hacienda señorial entre los años 1642 y 1670 . Pero también alude a que las casas de Feria y de Béjar comenzaron a ver disminuir sus ingresos antes del estallido del conflicto con Portugal y que la pérdida de rendimientos de las rentas señoriales fue muy generalizada y por ello no sólo achacable al factor bélico ${ }^{6}$.

La difícil situación financiera en la que se debatia el Estado de Feria propició que sus rentas fueran concursadas por la Hacienda Real durante un siglo, desde mediados del siglo XVII hasta mediados del XVIII:

"desde el 8 de julio de 1643 hasta que se ejecutó la Real Cédula de 23 de marzo de 1741, se mantuvo concursado (y mal administrado como el dro. presume) el Estado de Feria» ${ }^{7}$.

«que por casi cien años, desde 1643 estuvo en concurso el Estado de Feria, con dichas dos villas de Oliva y Valencia, y referidas tres dehesas de Xerez, hasta que se alzó en 1741 " $^{8}$.

\footnotetext{
${ }^{5} \mathrm{JAGO}, \mathrm{CH}$. "La crisis de la aristocracia en la Castilla del siglo XVIl», en Poder y sociedad en la España de los Austrias. Barcelona 1982, págs. 248-286.

${ }^{6}$ Jago menciona otros casos similares, pues en enero de 1647 el Consejo de Hacienda recibió un informe de Badajoz donde se notificaba que las rentas de pastoreo reales habian experimentado una aguda caída después de 1642 por la disminución de rebaños provocada por la guerra con Portugal. JAGo, CH., Art. cit, pág. 267.

7 AHMZ, FDF, carp. 465, leg.: Papel que demuestra lo que resulta en las pruebas instrumentales y de testigos hechas por la Casa en los autos sobre el justiprecio de lo que a SE pertenece en la dehesa del Campo y dictamen del abogado de Cámara a su consecuencia con fecha 7 nov. 1776

${ }^{8}$ Archivo Histórico Nacional, Consejos, leg. 31.461, Memorial Ajustado del Pleito de tanteo de Oliva y Valencia, folio $76 \mathrm{v}$.
} 
El siglo xvml sería más favorable para la economia del Estado de Feria. Santiago Aragón, que ha estimado unas rentas de este señorío en 550.000 reales en el año 1600, afirma que a comienzos del siglo xvIII éstas habian mermado considerablemente y durante el periodo 1706-1725 se mantuvieron en una renta modesta en torno a los 240.000 reales. Entre los años 1726 y 1755 crecieron moderadamente en torno a un 30 por $100^{\circ}$.

Para realizar una visión panorámica de la situación económica del Estado de Feria hemos elegido el año 1772, por hallarse en mitad del periodo a estudiar y poseer abundante información. Zafra era la principal y más poblada villa. En 1772 vivían en ella 1.683 vecinos, y en 1787 eran 5.351 habitantes. Su estratégica posición en la ruta comercial de Mérida a Sevilla justificaba que se hubiese convertido en la capital administrativa del señorio desde tiempos medievales. Había sido elegida por el primer conde de Feria para establecer en ella su residencia señorial. Posteriormente, con la unión del ducado de Feria al marquesado de Priego y al ducado de Medinaceli, los señores no residian en estas tierras y apenas visitaban sus dominios extremeños. En Zafra el duque era solamente señor jurisdiccional, sin base territorial alguna ${ }^{10}$. Por ello los ingresos más importantes procedian de las alcabalas, impuesto que gravaba todas las transacciones que se realizaban en la villa. Se diferenciaban dos grupos de alcabalas. Uno de ellos se arrendaba, bien al gremio que tenía la obligación de pagarlo o a una persona particular, que abonaba al Duque una cantidad anual fija durante el periodo de duración del contrato, y que se encargaba de recaudar el impuesto. Se integraban en este sistema las alcabalas de asiento de paños, curtidos, zapatería, aceite y jabón, vino y vinagre, carne, bestiaje, azúcar y cacao, lenceria, y las ventas realizadas en las ferias de San Juan y San Miguel. Otro grupo se gestionaba directamente por la Hacienda ducal a través del administrador de alcabalas. Se trataba de los ramos de viento de merceria, paños, frisas, hierro y herraje, madera, lino, esparto, carbón, venta de posesiones, padrón de vecindario y no nombrado.

Es primer grupo recaudó en 1772 una renta de 43.973 reales, siendo el de asiento de paños el ramo que aportó una cantidad más crecida de

\footnotetext{
9 Afagón Mateos, S., La nobleza extremeña en el siglo xvm. Mérida 1990, págs. 91-92.

${ }^{10}$ El único predio rústico en el que tenia derechos el Duque era la dehesa del Rincón, pero la habia donado al hospital de Santiago para que se atendiera, con el producto de sus rentas, a los enfermos pobres que ingresaran en él. Era dueño del alcázar, que se utilizaba entonces como sede de la contaduria y vivienda de los principales cargos administrativos. En el recinto de este edificio habia un pequeño jardin, y en sus inmediaciones una huerta denominada "Huerta Honda", de una fanega de tierra, con agua que se comunicaba de un pilar llamado "del duque» y una casa pequeña habitada por el jardinero del palacio. También le pertenecía una casa ubicada en el Campo de Sevilla.
} 
Las rentas del ducado de Feria en la segunda mitad del siglo xvIII

CUADRO 1. RENTAS DE LA CASA DUCAL EN ZAFRA EN EL AÑO 1772

\begin{tabular}{|c|c|}
\hline CONCEPTO & $\begin{array}{c}\text { RENTA ANUAL } \\
\text { (REALES) }\end{array}$ \\
\hline \multicolumn{2}{|l|}{ Alcabalas arrendadas: } \\
\hline 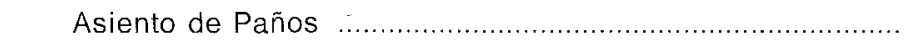 & 15.000 \\
\hline Curtiduría & 3.900 \\
\hline 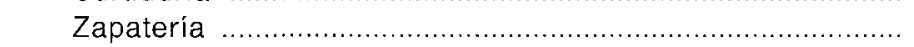 & 1.819 \\
\hline Aceite y jabón ............................ & 2.600 \\
\hline Vino y vinagre ........ & 4.220 \\
\hline Carne y bacalao ..... & 5.367 \\
\hline Bestiaje ................................ & 1.832 \\
\hline 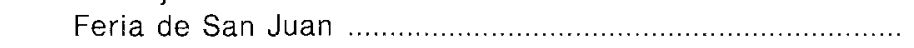 & 2.314 \\
\hline 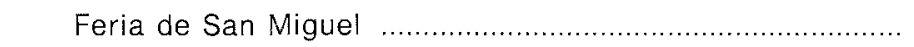 & 4.852 \\
\hline 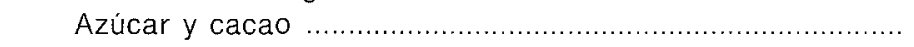 & 733 \\
\hline 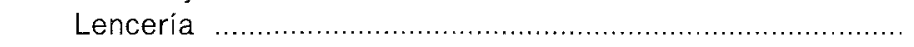 & 995 \\
\hline 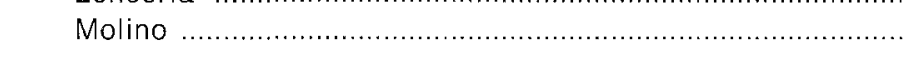 & 341 \\
\hline SUBTOTAL & 43.973 \\
\hline 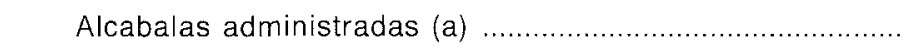 & 29.720 \\
\hline Renta del Fiel Almotacén & 739 \\
\hline 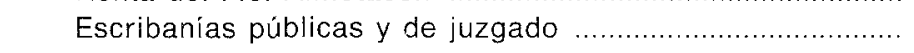 & 800 \\
\hline TOTAL DE RENTAS & 75.384 \\
\hline
\end{tabular}

(a) Viento de mercería, paños, frisas, hierro y herraje, madera, lino, esparto, carbón, venta de posesiones e imposición de censos, repartimiento de padrón de vencindario, y no nombrado.

Fuente: Archivo Histórico Municipal de Zafra - Fondo Documental del ducado de Feria (FDF), C. 167, leg. 28. Rentas del Duque en 1772.

ingresos: 15.000 reales. El grupo de alcabalas administradas consiguió reunir 29.872 reales. El total de alcabalas supusieron 73.845 reales, el 73,8 por ciento de todas las rentas percibidas por este concepto, lo que da una idea de la importancia comercial de esta villa en el conjunto del ducado.

Las escribanías eran un pequeño capítulo de las rentas, pues solamente contribuian con 800 reales al año. Zafra era uno de los pueblos que proporcionaba más dinero a las arcas del ducado en la segunda mitad del siglo xvill y su porcentaje de participación en 1772 era del 16 por ciento.

En un grupo de seis villas los ingresos de la casa ducal constituían escasa relevancia en 1772 , pues al igual que en Zafra, el Duque era so- 
lamente señor jurisdiccional. En el caso de Feria, La Morera y Alconera únicamente cobraba las alcabalas, en La Torre de Miguel Sexmero y Almendral se añadian a estas rentas los escasos reales de la escribanía. Las alcabalas de estas villas en conjunto, solamente sumaban 12.690 reales, lo que denota el escaso comercio que se realizaba en ellas. El procedimiento de cobro para este impuesto era el arrendamiento a los ayuntamientos por una cantidad fija anual, que se mantenia durante un largo periodo de tiempo. El concejo pagaba al Duque a final de año la cantidad estipulada, y este dinero se obtenía en la mayoría de las villas del fondo de propios. Con este sistema de encabezamiento de alcabalas el Duque se ahorraba personal administrativo y recaudatorio, amén de asegurarse una renta fija que no estaría mediatizada por el volumen de transacciones anuales. El pueblo salia ganando también, pues el pago fijo estaría por debajo del que se debía aportar en caso de vigilar cada una de las transacciones realizadas. La villa menos rentable para la casa de Feria era Salvatierra, que apenas daba 500 reales, pues el Duque no tenia alli derecho a percepción de alcabalas, y únicamente cobraba la escribanía y el arriendo de unos cercados.

En La Parra pertenecian al Duque las alcabalas de la villa y las de todas las ventas realizadas por los forasteros en la feria de San Bartolomé. Asimismo, era dueño de una dehesa Ilamada El Salamanco, era de monte alto y bajo, poblada de encinas y alcornoques, toda su tierra era de infima calidad, por ello las hierbas se arrendaban al precio de 8.500 reales. Las rentas del pueblo al ducado sumaban en 1772 la cantidad de 13.491 reales.

En Salvaleón, además de las aicabalas y escribanias, se cobraba un censo sobre la dehesa del Monte de Porrino y Valmojado, debido a un pleito que sobre la pertenencia de estas posesiones y la denominada Caballerías de las yeguas y los Méndez, siguieron la villa y D. Gomes Suárez de Figueroa, primer duque de Feria, en época en que aún era conde. Para su solución las partes firmaron una escritura de concordia en 1563 , en la que la villa se obligó a pagar anualmente 5.000 reales. Dentro del término de Salvaleón se ubicaban dos dehesas denominadas La Bejarana y Palacio, con jurisdicción separada de la villa. Eran dehesas de pasto, labor y bellota. La de Palacio tenia tres cuartos de legua de largo y media de ancho, era de monte alto y bajo, la mayor parte de alcornoques, aunque también habia algunas encinas; le pertenecian al Duque todos los diezmos de ganado y de grano. La arrendaba a pasto y labor, sin distinción, y en 1772 percibia 22.000 reales. Dentro de ella había dos huertas unidas, que poseian un molino cada una, que se arrendaban por 1.180 reales. La dehesa de Bejarana tenía media legua de largo e igual medida de ancho, era de pasto, labor y bellota, con monte alto y bajo, predom:- 
Las rentas del ducado de Feria en la segunda mitad del siglo xvIII

CUADRO 2. LAS VILLAS QUE APORTABAN MENOS INGRESOS AL DUCADO DE FERIA EN 1772

\begin{tabular}{|c|c|c|}
\hline VILLA & TIPO DE RENTA & $\begin{array}{c}\text { REALES } \\
\text { VON. }\end{array}$ \\
\hline FERIA & 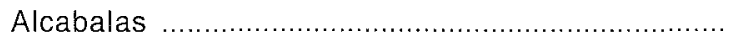 & 3.600 \\
\hline LA MORERA & Alcabalas & 1.350 \\
\hline \multirow[t]{3}{*}{ LA TORRE } & Alcabalas $\ldots \ldots \ldots \ldots \ldots \ldots \ldots \ldots$ & 1.800 \\
\hline & 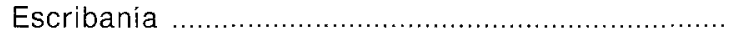 & 50 \\
\hline & 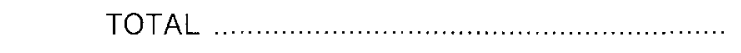 & 1.850 \\
\hline \multirow[t]{3}{*}{ ALMENDRAL } & Alcabalas. & 4.200 \\
\hline & Escribanía. & 225 \\
\hline & 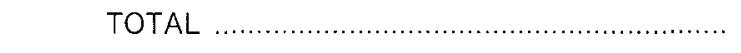 & 4.425 \\
\hline ALCONERA & 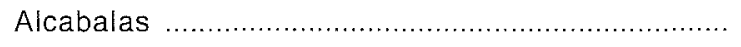 & 912 \\
\hline \multirow[t]{3}{*}{ SALVATIERRA } & 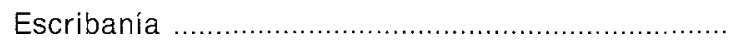 & 300 \\
\hline & 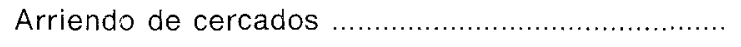 & 253 \\
\hline & TOTAL & 553 \\
\hline
\end{tabular}

Fuente: AHMZ-FDF, C. 167, leg. 28. Rentas del ducado en 1772.

CUADRO 3. RENTAS DUCALES EN LA VILLA DE LA PARRA EN 1772

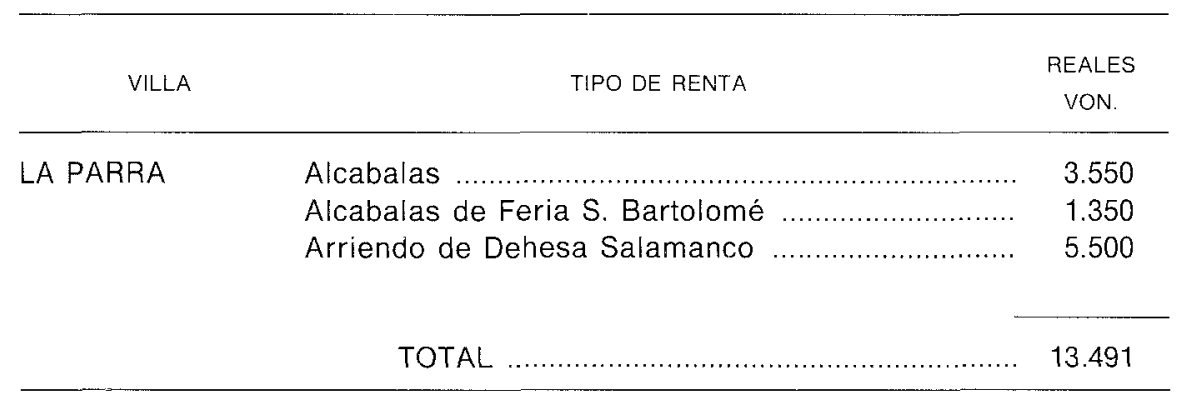

Fuente: AHMZ-FDF, C. 167, leg. 28. Rentas ducado 1772. 
naba la encina, con algún alcornoque; su arriendo producia 16.000 reales al año a la hacienda ducal".

En Nogales pertenecian al Duque las alcabalas y escribanía de la villa, además era dueño de los baldios de la villa, tanto de labor como montuosos; los primeros se repartian en suertes a los vecinos para su cultivo y labranza, quienes recibian un título con la obligación de pagar la novena parte de los granos que recogiesen. Los rastrojos de estas tierras los había cedido el Duque a los vecinos, pero se los cobraba a los labradores forasteros. Arrendaba una huerta llamada de las Moreras, de 2 fanegas de extensión, y percibia un censo sobre un molino harinero. En el término de Nogales se hallaba la dehesa de Santa Justa de tres cuartos de legua de largo y legua y media de ancho, era de pasto, labor y bellota, y en ella estaban incluidos los sitios de Entrin del Medio y Entrin Bajero y Maricara. En realidad se trataba de varias dehesas que se arrendaban de forma conjunta. Se labraban en hojas, percibiendo la Casa de Feria la novena parte de granos y el importe de los rastrojos. Los ingresos producidos por la dehesa eran de 24.715 reales, y lo recaudado en esta villa ascendia a la apreciable cantidad de 46.698 reales.

Los ingresos ducales en las villas de Oliva de la Frontera y de Valencia del Mombuey representaban una magnitud bastante apreciable. En estas villas, que serán las más combativas de todas por defender sus derechos, poseía la Casa de Feria el señorio pleno.

Oliva era la mayor de las dos. Habitaban en ella 536 vecinos, en el año 1772, por ello estimamos que su población era de unos 2.144 habitantes, lo cual la convertía en la segunda en importancia del ducado, después de Zafra.

Por el ejercicio directo de la jurisdicción percibia el Duque una serie de rentas de exigua entidad económica, pero con un hondo simbolismo señorial. Éstas eran 100 reales anuales aportados por el ayuntamiento en concepto de derechos de secretaría en la elección de oficios concejiles, 40 reales al gobernador del Estado de Feria y 60 reales por el arriendo de la escribanía pública. En muchas ocasiones el contador no especificaba los dos primeros conceptos, probablemente porque los englobara en otras partidas.

AHMZ, FDF, carp. 186, leg. 5: Forrnación de relaciones del catastro, años 1552 y 1771 , Unica Contribución, Doc: Relación de los bienes que pertenecen al Duque en la Villa de Salvaleón, 1552. Doc: Relación de las pertenencias del Duque en las Dehesas de Palacio y Bejarana. 
Las rentas del ducado de Feria en la segunda mitad del siglo xvill

CUADRO 4. RENTAS DE LA HACIENDA DUCAL EN LOS TÉRMINOS DE SALVALEÓN Y NOGALES EN EL AÑO 1772

\begin{tabular}{|c|c|c|}
\hline VILLA & TIPO DE RENTA & $\begin{array}{c}\text { REALES } \\
\text { VON. }\end{array}$ \\
\hline \multirow[t]{2}{*}{ SALVALEÓN } & $\begin{array}{l}\text { Alcabalas } \\
\text { Escribania } \\
\text { Censo dehesa Monte Porrino }\end{array}$ & $\begin{array}{r}2.600 \\
50 \\
5.000\end{array}$ \\
\hline & 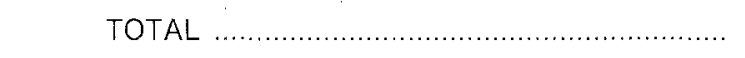 & 7.650 \\
\hline $\begin{array}{l}\text { DEHESA } \\
\text { BEJARANA } \\
\text { DEHESA }\end{array}$ & 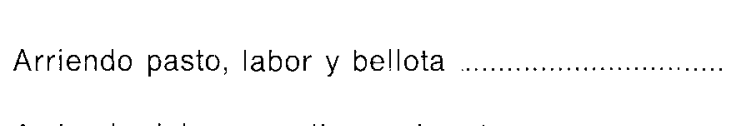 & 16.100 \\
\hline PALACIO & Arriendo dehesa, molinos y huertas ..... & 23.118 \\
\hline NOGALES & $\begin{array}{l}\text { Alcabalas } \\
\text { Escribania } \\
\text { Dehesas Sta. Justa, Maricara y Ent. } \\
\text { Rastrojeras de dehesas } \\
\text { Novenos de grano } \\
\text { Huerta de las Moreras } \\
\text { Censo de molino harinero }\end{array}$ & $\begin{array}{r}1.220 \\
20 \\
24.715 \\
4.670 \\
15.639 \\
300 \\
132\end{array}$ \\
\hline & TOTAL ..................... & 46.696 \\
\hline
\end{tabular}

Fuente: AHMZ - FDF - C. 167, leg. 28. Rentas ducado 1772.

El Duque poseía en Oliva el derecho de cobrar las alcabalas, como en casi todas las villas del Estado, que arrendaba el ayuntamiento en 2.020 reales al año.

Un capítulo de gran importancia era el de los impuestos sobre el producto agrícola. La Casa de Feria tenía derecho al diezmo y la primicia del trigo, cebada, avena y centeno; al diezmo de habas y garbanzos recogidos por los labradores en todo el término; y al medio terrazgo de lo recolectado en el terreno dedicado al cultivo en la dehesa del Campo.

Como impuesto sobre la ganadería y sus productos derivados se pagaban los diezmos de lechones, borregos, chivos, lino, lana, queso, pollos, barro labrado, miel, cera y flores. Los ganaderos transhumantes que traían los ganados a los términos de Oliva y de Valencia del Mombuey, por razón del diezmo de "arrealas de serranos» pagaban de cada cincuenta ovejas paridas una con su cría, una de cada doscientas ovejas horras, y uno de cada veinte chivos. Sus productos se regulaban en especie de ganado y los restos se cobraban en dinero, al valor de lo arrendado por las cabezas de ganado enteras. A este resto se le llamaba «re- 
CUADRO 5. LAS RENTAS DEL DUCADO DE FERIA EN OLIVA Y VALENCIA DEL MOMBUEY EN EL AÑO 1772

\begin{tabular}{|c|c|c|}
\hline$V I L L A$ & TIPO DE RENTA & $\begin{array}{l}\text { REALES } \\
\text { VON. }\end{array}$ \\
\hline \multirow{9}{*}{$\begin{array}{l}\text { OLIVA DE LA } \\
\text { FRONTERA }\end{array}$} & Alcabalas ........ & 2.000 \\
\hline & 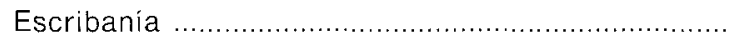 & 60 \\
\hline & Diezmos, primicias $1 / 2$ terrazgos de grano ........... & 22.420 \\
\hline & 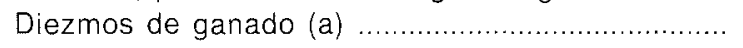 & 18.255 \\
\hline & 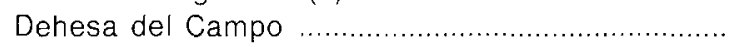 & 23.865 \\
\hline & Huerto de Pomar & 250 \\
\hline & 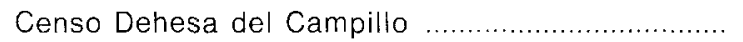 & 44 \\
\hline & Arriendo de casa & 100 \\
\hline & 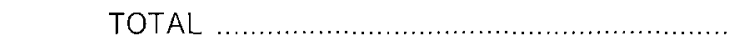 & 67.016 \\
\hline \multirow{6}{*}{$\begin{array}{c}\text { VALENCIA DEL } \\
\text { MOMBUEY }\end{array}$} & 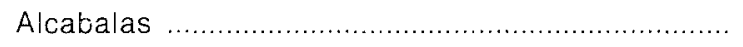 & 500 \\
\hline & 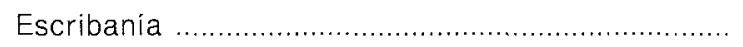 & 20 \\
\hline & Diezmos, primicias y $1 / 2$ terrazgos de grano ........ & 16.631 \\
\hline & 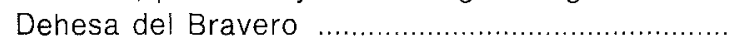 & 5.900 \\
\hline & 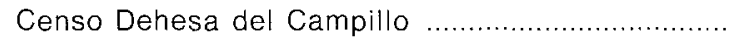 & 44 \\
\hline & TOTAL ........ & 23.095 \\
\hline
\end{tabular}

(a) Esta partida incluye conjuntamente los diezmos de ganado de las dos villas.

Fuente: AHMZ, FDF, C. 167. leg. 28. Rentas ducado 1772.

bujales». Todos estos diezmos se recaudaban junto a los de Valencia del Mombuey.

Cobraba la hacienda ducal un censo perpetuo enfitéutico, en señal de señorío y directo dominio, sobre una dehesa comunera de Oliva y Valencia, denominada del Campillo. Estaba divida para su aprovechamiento, de tal modo que las dos terceras partes eran para Oliva y una tercera parte para Valencia. El rédito de este censo era de escasa significación, solamente 44 reales y 4 maravedies para cada una de las dos poblaciones.

El huerto de Pomar, de media fanega de extensión, se arrendaba a vecinos del pueblo por 250 reales al año.

Sin duda, la propiedad más interesante del Duque era la dehesa del Campo. De una extensión de 7.850 fanegas, era de pasto, labor y bellota, con monte alto y bajo de encinas, alcornoques y jarales. Se trataba de un condominio del Duque y del Común de vecinos. Correspondían a la Casa 
de Feria los aprovechamientos de hierbas y pastos de invernada, desde el dia de San Miguel - 29 de septiembre - de un año hasta el 25 de marzo del siguiente; y el granillo de bellota. El Común de vecinos tenia derecho a disfrutar la bellota y el aprovechamiento de hierbas y pastos de primavera y agostadero, desde el 25 de marzo hasta el 29 de septiembre. En el año 1777 el Común de vecinos arrendaba los derechos del Duque en este precio por 23.867 reales. Un grupo de vecinos poseía el derecho de siembra en las dehesas de las villas. Las tierras de labor de las dehesas se repartian entre ellos con títulos de por vida, hereditarios. A cambio debian pagar la midad de los terrazgos que producian los años que se sembraba; se estipulaban en una fanega de cada veinte que se cosechaba. Los datos globales de Oliva en 1772 arrojaban una cifra de 67.016 reales ${ }^{12}$, con lo cual era la tercera villa del ducado por su aportación a la Hacienda señorial, después de Zafra y Santa Marta.

Valencia del Momibuey tenía menos importancia, pues su término era más pequeño y estaba menos poblada. Moraban en ella 132 vecinos en 1772, unos 528 habitantes. El Duque cobraba lo mismo que en Oliva en concepto de secretaría, idéntica era la circunstancia del pago al gobernador del Estado, y la escribanía daba la insignificante cantidad de 20 reales. Se recaudaban los mismos impuestos sobre el producto agrícola que en Oliva, es decir los diezmos y primicias de los granos y semillas de lo labrado en todo el término y la mitad de los terrazgos de la dehesa del Bravero, que en 1772 tuvieron un valor de 16.631 reales, siendo la principal fuente de ingresos de la casa. Para los diezmos de ganados y productos derivados se utilizaban los mismos criterios que para la otra población, y se recaudaban juntos, de tal forma que nos es difícil conocer su importancia económica.

La dehesa del Bravero era un condominio del Duque y el Común de vecinos, con idéntico reparto de derecho que hemos glosado para la dehesa del Campo de Oliva. Tenia una extensión de 2.200 fanegas de tierra, era cerrada, de pasto, labor y bellota, de monte alto y bajo de encinas y con algunos alcornoques. En 1772 el Común pagaba 5.900 reales por el arriendo de los derechos de la Casa de Feria. El Duque tenía concedido títulos a labradores para que trabajasen las tierras de la dehesa susceptibles de cultivo y a cambio le pagaban la mitad de los terrazgos. Todos los conceptos que hemos analizado suponían en esos momentos 23.095 reales al año.

\footnotetext{
12 Bien es verdad que a esta cantidad habria que restarle la parte de diezmos de ganado de Valencia del Monbuey, pues al recaudarse unidos se incluyeron en la cuenta de Oliva.
} 


\section{LAS RENTAS DEL MARQUESADO DE VILLALBA}

El Duque era dueño del señorío pleno del marquesado de Villalba que integraban Santa Marta, Villalba, Solana y Corte de Peleas. En este concepto la contaduría argumentaba que a la Casa de Feria le pertenecian todas las tierras de labor y monte de sus términos, a excepción de algunos cercanos a los pueblos, aunque esta tajante afirmación le será discutida por los pueblos y dará lugar a pleitos de los que nos ocuparemos en capitulo aparte. Lo cierto es que las tierras de labor las repartía en suertes para su cultivo y labranza a sus respectivos habitantes y a los forasteros.

- En Villalba, a los de Feria, La Parra y Aceuchal.

- En Santa Marta, a los de Feria, La Parra, La Morera y Aceuchal.

- En Solana, a los de Aceuchal.

- En Corte de Peleas, a los de La Parra y Santa Marta.

Por el disfrute de estas tierras pagaban la novena parte del trigo, de la cebada y del centeno. Asimismo, pertenecian al Duque el medio diezmo de granos y semillas en los sitios del Hebrero, Pancho, Machial y Turruñuelo en Santa Marta, y de todas las tierras del término de Solana, a excepción del Reejido. Estos ingresos resultaban los más interesantes del marquesado, pues sus tierras, muy cerealistas, daban buenas cosechas. En 1772 se recaudaron en Villalba 24.136 reales, en Santa Marta 63.603 y en Solana 14.768 reales, que arroja un total de 102.507 reales, es decir el 77,8 por 100 de todos los ingresos de la Casa de Feria en el marquesado. Completaban las rentas agrícolas los derechos de rastrojos, que habian de pagar los labradores que consiguiesen tierras en los pueblos del marquesado sin ser vecinos de ellos.

El segundo capitulo de ingresos del marquesado, por orden de importancia, lo constituían los novenos de ganado. Parece ser que este derecho procedía de que en época bajomedieval los señores del Estado de Feria dieron tierras, dehesas boyales, ejidos, montes y baldios a los concejos de las villas del marquesado de Villalba, a cambio de que pagasen los vecinos la novena parte de todos los ganados, lana, queso y aves que se criasen. Las especies de ganado que habian de abonar el noveno eran los borregos, chivos, becerros, potros, jumentos y cerdos, y contaban el año desde Pascua de Resurreción hasta el Sábado Santo. En 1772 se cobraron 8.157 reales por este concepto. 
Las rentas del ducado de Feria en la segunda mitad del siglo xvm!

CUADRO 6. LAS RENTAS DE LA CASA DE FERIA EN EL MARQUESADO DE VILLALBA EN EL AÑO 1772

\begin{tabular}{|c|c|c|}
\hline VILLA & TIPO DE RENTA & $\begin{array}{c}\text { REALES } \\
\text { VON. }\end{array}$ \\
\hline \multirow[t]{2}{*}{ VILLALBA } & $\begin{array}{l}\text { Alcabalas } \\
\text { Escribanía } \\
\text { Novenos de grano } \\
\text { Novenos de ganado del marquesado } \\
\text { Rastrojos }\end{array}$ & $\begin{array}{r}800 \\
30 \\
24.136 \\
8.157 \\
4.128\end{array}$ \\
\hline & 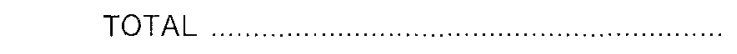 & 42.251 \\
\hline \multirow[t]{2}{*}{ SANTA MARTA } & 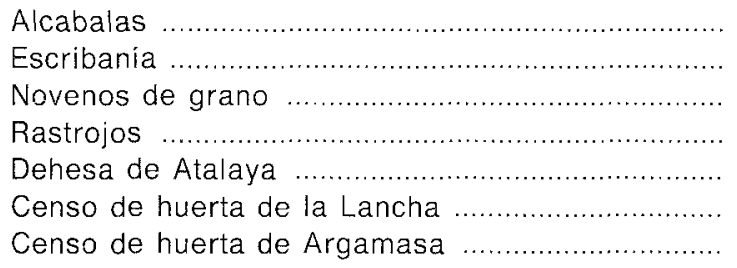 & $\begin{array}{r}1.650 \\
28 \\
63.603 \\
5.854 \\
1.575 \\
120 \\
40\end{array}$ \\
\hline & TOTAL . & 72.870 \\
\hline \multirow[t]{2}{*}{ SOLANA } & 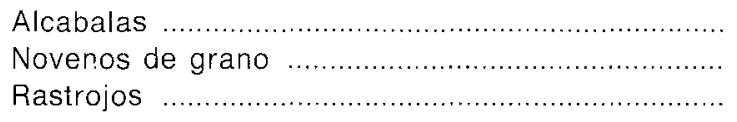 & $\begin{array}{r}480 \\
14.768 \\
1.294\end{array}$ \\
\hline & TOTAL & 16.542 \\
\hline
\end{tabular}

CORTE DE PELEAS: Las alcabalas no producen nada y los novenos de grano y rastrojos están incluidos en los de Santa Marta.

Fuente: AHMZ-FDF, C. 167, leg. 28. Rentas ducado 1772.

Las rentas se completaban con el cobro de alcabalas, que se efectuaba con la excepción de Corte de Pelas, por la escasez de vencindario, pues según datos manejados por el contador en 1772 solamente cinco vecinos vivían en ella. Además, se cobraba el arriendo de las hierbas de la dehesa de Atalaya y varios censos en Santa Marta.

Los ingresos que aportaba el marquesado a las arcas del Duque eran importantes, pues Santa Marta fue en 1772 la segunda villa de todo el Estado por su contribución a la hacienda ducal, mientras que Villalba ocupaba el quinto lugar. 


\section{OTROS INGRESOS}

Aparte de los derechos y rentas del Duque en el Estado de Feria, eran de su propiedad varios censos y dehesas situados fuera de este entorno jurisdiccional, en otras villas y ciudades extremeñas.

Poseía tres censos perpetuos de poca entidad: uno sobre la huerta de la Argamasa, en Medina de las Torres; otro sobre varias suertes de tierra, en Talavera la Real; y un tercero sobre tierras del Pedernal, en Mérida. Suponian unas rentas de 58,941 y 1.500 reales, respectivamente. Sin embargo, las dehesas se arrendaban por importantes cantidades de dinero, que aumentarán sensiblemente en los últimos veinticinco años de siglo, en paralelismo a la creciente demanda de tierras. El Duque era propietario de tres dehesas en villas que no se ubicaban en sus dominios: la del Redrojo, la del Rincón de Almorchón, y la de Matilla, Monturque y Marihernández.

La dehesa del Redrojo, en término de Rivera del Fresno, formaba parte de la dehesa Real de la Serena. Don Luis Antonio Fernández de Córdoba-Figueroa, décimo duque de Feria y undécimo de Medinaceli, la compró en 1756 a la Mesa Maestral de la Orden de Santiago por la suma de 956.250 reales; aunque en realidad le fue entregada por el Consejo de Castilla como parte del reintegro de las alcabalas de la ciudad de Montilla y otros pueblos del marquesado de Priego, que habian sido incorporados a la corona.

La dehesa del Rincón de Almorchón, en términos de Cabeza del Buey, era asimismo propiedad del Duque. Uno de sus millares, que al igual que la dehesa del Redrojo había formado parte de la dehesa Real de la Serena, y pertenecía a la Orden de Alcántara, fue otorgado en la misma fecha por precio de 216.019 reales y 21 maravedis al mismo Duque también como parte de pago de las alcabalas de Montilla ${ }^{13}$.

Esta serie de adquisiciones de dehesas por parte del duque de Medinaceli hemos de contemplarla como parte de un proceso de progresiva señorialización de algunos territorios de Extremadura pertenecientes a las órdenes militares, que se produjo a lo largo de los siglos XVI al XVIII. Ángel Rodríguez Sánchez, sinteǐizando las investigaciones realizadas por

\footnotetext{
${ }^{19}$ AHMZ, FDF, legajo 07-1(4)-6. Expediente sobre intentar labradores de Cabeza del Buey dividir en hojas la dehesa de Almorchón.
} 
Las rentas del ducado de Feria en la segunda mitad del siglo xvII'

CUADRO 7. RENTAS DE PROPIEDADES DE LA CASA DUCAL UBICADAS FUERA DEL ÁMBITO JURISDICCIONAL DEL ESTADO DE FERIA EN 1772

\begin{tabular}{|c|c|c|}
\hline VILLAS & TIPO DE RENTAS & $\begin{array}{c}\text { REALES } \\
\text { VON. }\end{array}$ \\
\hline \multicolumn{3}{|l|}{ MEDINA DE LAS } \\
\hline TORRES & Censo sobre huerta Argamasa .. & 59 \\
\hline \multicolumn{3}{|l|}{ TALAVERA LA } \\
\hline REAL & 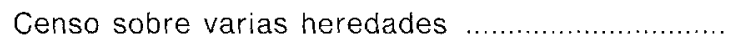 & 941 \\
\hline MÉRIDA & 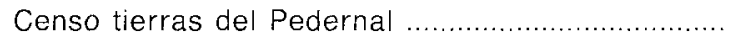 & 1.500 \\
\hline \multicolumn{3}{|l|}{ RIVERA DEL } \\
\hline FRESNO & Dehesa de Redrojo & 28.500 \\
\hline \multicolumn{3}{|l|}{ CABEZA DEL } \\
\hline \multirow[t]{6}{*}{ BUEY } & 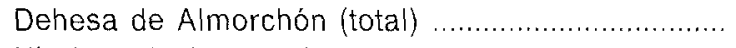 & 44.820 \\
\hline & $\begin{array}{l}\text { Hierbas de invernadero arr. a don Fernando de } \\
\text { LLano }\end{array}$ & 36.542 \\
\hline & Un millar de la dehesa de Almorchón ................... & 5.845 \\
\hline & 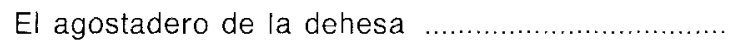 & 1.653 \\
\hline & 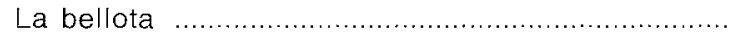 & 480 \\
\hline & 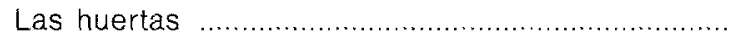 & 300 \\
\hline \multicolumn{3}{|l|}{ JEREZ DE LOS } \\
\hline CABALLEROS & Dehesa de Monturque, Mantilla y Marihernández & 10.000 \\
\hline \multirow[t]{2}{*}{ LOBÓN } & 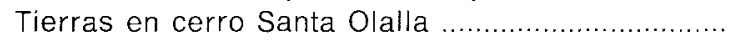 & 674 \\
\hline & TOTAL DE RENTAS .... & 86.494 \\
\hline
\end{tabular}

Fuente: AHMZ - FDF - C. 167, leg. 28. Rentas Duque 1772. Idem, 07-14-6. Expediente sobre intentar labradores de Cabeza del Buey dividir en hojas la dehesa de Almorchón.

Cepeda Adán, Cardalliaguet y Fernández Nieva ${ }^{14}$, afirma que durante los reinados de Carlos I y Felipe II hubo privatizaciones de tierras extremeñas que habian pertenecido a las órdenes militares y que muchos de estos lugares también pasaron a convertirse en patrimonio del poder señorial. Así, las encomiendas más productivas fueron acaparadas por los miembros de la familia real, la alta nobleza y los banqueros extranjeros.

\footnotetext{
${ }^{14}$ Cepeda, J., «Desamortización de tierras de las Órdenes Militares en el reinado de Carios 1", Hispania, 146, 1980, págs. 487-528; CARDALliaguet, M., "Jurisdicciones señoriales de Extremadura en el siglo xvl", en $V$ Congreso de Estudios Extremeños. Badajoz 1974; FERNÁNDEZ NIEVA, J., "Las Órdenes Militares en la Extremadura moderna. Encomiendas, dehesas y rentas de la Orden de Santiago a principios del siglo xvIII", en / Jornadas de Historia de Extremadura. La Tierra. Cáceres 1979 (inédito); «La Orden de Alcảntara en la Extremadura moderna, notas y documentos para su historia", en Campo Abierto, I, 1982.
} 
Por lo menos 45 comunidades de vasallos modificaron su situación jurisdiccional en los siglos XVI al XVIII ${ }^{15}$. Fernández Nieva ha demostrado cómo las encomiendas de Zalamea y Ceclavín pertenecian en 1744 al Infante D. Felipe, de las que obtenia rentas que superaban los 75.000 reales al año, el capitán del ejército D. Francisco Aranda era dueño de Eljas, y obtenía 15.000 reales, y Acehuche pertenecia a la condesa doña Rosa de Silva y Pimentel con una renta similar a la anterior ${ }^{16}$. A juzgar por las quejas de los vecinos de los pueblos afectados por el mencionado proceso de señorialización, y por las menciones realizadas en el Memorial Ajustado de Vicente Paíno, éste fue perjudicial para el desenvolvimiento económico de la provincia de Extremadura, y contribuyó no poco a su despoblación y subdesarrollo ${ }^{17}$.

La dehesa del Redrojo se arrendaba en 1772 por 28.500 reales y la del Rincón de Almorchón por 40.685, aunque la renta del quinquenio era algo inferior, 36.542 reales. Aparte se arrendaba uno de los millares de la dehesa por 5.845 reales, el agostadero de la dehesa que producia 1.653, la bellota 480 y las huertas 300 ; con ello los ingresos de la dehesa del Rincón de Almorchón sumaban 44.820 reales.

Respecto a la tercera dehesa, denominada de Monturque, Matilla y Marihernández, situada en el término de Jerez de los Caballeros, aportaba 10.000 reales, en ella se incluían cliatro huertas, que en ocasiones se arrendaban por separado.

El inicial análisis que hemos realizado de las rentas del Estado de Feria en 1772 nos permite establecer algunas consideraciones. La primera es la diferenciación de varios espacios geográficos distintos según las rentas percibidas.

En el ducado de Feria:

- Zafra, capital del señorio, que aportaba con sus alcabalas un contingente importante, debido a la pujanza de su comercio y de su artesania.

- Un grupo de villas en las que el Duque, como señor meramente jurisdiccional, percibía únicamente las alcabalas de muy escasa cuantía, solamente acompañadas, en ocasiones, por las exiguas rentas

15 Rodriguez Sanchez, A., "Extremadura: La tierra y los poderes", en Historia de Extremadura, t. III, Los tiempos Modernos. Badajoz 1985, pág. 468.

${ }^{16}$ Fernández Nieva, J., "La Orden de Alcántara en la Extremadura moderna. Notas y documento para su historia", en Campo Abierto. I, 1982, pág. 157.

17 VILAR, P., Catalunya dins L'Espanya moderna. Barcelona 1966, t. III, pág. 537. 
de las escribanias. Era el caso de Feria, La Morera, La Torre de Miguel Sexmero, Almendral y Alconera. En Salvatierra, ni aún se cobraban alcabalas. Por tanto las rentas de estas villas carecian de importancia para la economía ducal.

- A la villa de La Parra la consideramos de transición, pues el hecho de celebrarse en ella una feria ganadera en la que el Duque cobraba alcabalas y poseer en ella una dehesa, elevada las rentas a mayor cuantia.

- Un grupo de cuatro villas: Salvaleón, Nogales, Oliva y Valencia, en las que el Duque era titular del señorio mixto, y por ello se ingresaban en sus arcas sustanciosas rentas que provenían de cobro de derechos en especie, censos y arriendos de sus dehesas.

En el marquesado de Villalba el Duque tenía asumido el señorio mixto, y era dueño de gran parte del término de sus cuatro villas de Villalba, Santa Marta, Solana y Corte de Peleas. Las rentas, producidas por sus buenas tierras cerealistas y por los derechos de los ganados que se alimentaban de sus pastos, eran elevadas.

La segunda y postrera consideración a reseñar: la importancia indudable que comenzaban a tener, en la segunda mitad del siglo XVIII, las rentas de las posesiones ducales que se situaban fuera del marco jurisdiccional del Estado de Feria. Principalmente hemos de destacar las dehesas, dos de las cuales le habían sido entregadas por el Consejo de Castilla en compensación a la incorporación a la corona de la villa de Montilla, perteneciente al marquesado, de Priego. Aunque en sentido estricto éstas eran posesiones del citado marquesado, la gestión económica y su vigilancia se llevaba a cabo a través de la contaduría de Zafra. Arrendados estos predios a trashumantes mesteños comenzaban en esta época a producir sustanciosas cantidades de dinero.

\section{EVOLUCIÓN DE LAS RENTAS EN LA SEGUNDA MITAD DEL SIGLO XVIII}

La evolución de las rentas del Estado de Feria en la segunda mitad del siglo XVIII se nos aparece como positiva, pues de 293.181 reales de ingresos anuales medios en el cuatrienio 1751-54, se finaliza el siglo con valores medios superiores a los 600.000 reales anuales. Esto supone que entre el primer y último año de la serie estudiada se produjo un aumento de más del doble de las rentas. 
LAS RENTAS DEL DUCADO DE FERIA EN LA SEGUNDA MITAD DEL SIGLO XVIII

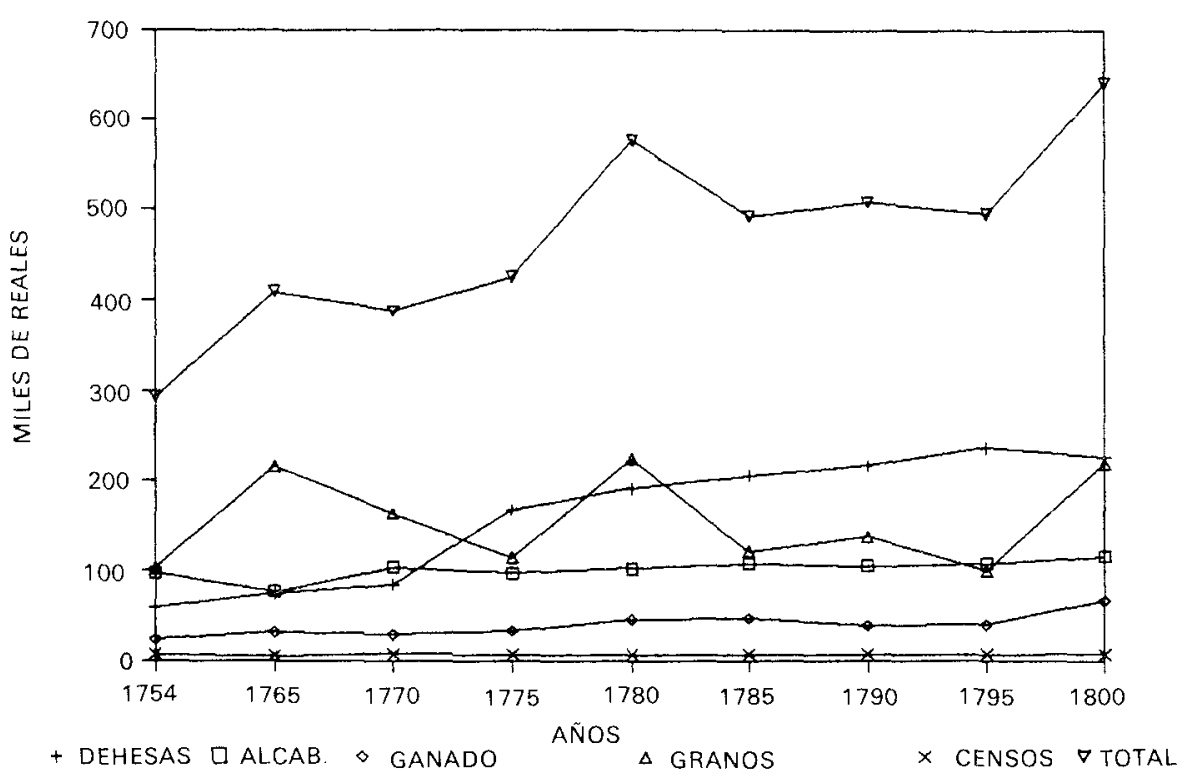

La primera cuestión que se nos plantea es si este aumento de los ingresos ducales se corresponde o no con una pareja evolución al alza de los precios de los productos agricolas. Pierre Vilar llega a la conclusión de que los ingresos señoriales en Cataluña durante el siglo Xvill poseen una extraordinaria vitalidad, pues quintuplican su caudal en esa centuria, mientras que los precios agricolas se multiplicaron por tres en el mismo período ${ }^{17}$. Torras Elías, que ha estudiado las rentas de los Medinaceli en Cataluña durante el siglo XVIII, matiza esta apreciación de Vilar y argumenta que si se observa solamente el último tercio o el último cuarto de siglo el panorama cambia, pues el ingreso señorial en su conjunto creció menos que los precios. Pone para ello ejemplo del valor global de veinticuatro arrendamientos de los Medinaceli, que entre 1772-1775 y 1798 y 1801 creció un 59 por 100, mientras que el índice de los precios agricolas to hizo en un 71 por 100. Para él lo más sustancial del incremento de la renta señorial habia sucedido en los dos primeros tercios de siglo, y culminó entre 1760 y 1780 . A partir de entonces parece haber perdido su dinamismo. Lo atribuye a que el estancamiento de la producción y de 
la comercialización de los granos inmovilizó esta parte de los ingresos señoriales, que se habia manifestado con gran vitalidad hasta este momento, por ello no pudo seguir el ritmo de alza de precios ${ }^{18}$.

Earl J. Hamilton, que ha estudiado de una manera concienzuda los precios en España desde la segunda mitad del siglo XVII hasta el final del XVIII, argumenta que si se calculase la subida de los precios de los cereales durante últimos tres cuartos del siglo xvill comparando los del período 1716-1725 con los de 1796-1800, se comprobaría que la cebada ocupaba el primer puesto en Castilla la Nueva, con un crecimiento del 290 por 100, seguida del trigo con el 285 por 100 de los garbanzos con un 250 y del arroz con un 125 por 100 de aumento. En Castilla la Vieja-León los incrementos fueron: centeno 350 por 100 , trigo 340 por 100 , cebada 285 por 100 y arroz 120 por 100 . En Andalucía la cebada subió casi el 370 por 100 y los garbanzos el 205 por $100^{19}$.

Por los datos que poseemos de los precios de los productos agrícolas en las villas del Estado de Feria, no parece que la inflación llegara a ser tan espectacular como atribuye Hamilton para otras regiones de España. Sin querer ser exhaustivo y reconociendo que es necesario un estudio en profundidad de la evolución de los precios en Extremadura en el siglo xvill, podemos hacer algunas observaciones al respecto. En $1753 \mathrm{el}$ precio del trigo fluctuaba entre los 28 y 30 reales en Oliva y Valencia, y los 32 a 50 en Santa Marta. La cebada se cotizaba de 18 a 20 reales en Oliva, de 19 a 21 en Santa Marta, y de 20 reales en Villalba. Estos datos nos permiten obtener un precio medio de trigo de 34,6 reales y de 19,6 reales para la cebada. Comparándolos con los de Oliva y Valencia del Mombuey del periodo 1768-1778 no se observa una diferencia muy sustancial. Pues el precio medio del trigo fue de 31,8 reales. Aunque con una gran fluctuación desde los 20 reales de los años 1771 a 1773 y los 46 reales en que se vendió este producto en 1769 y 1775 . El precio medio de la cebada fue de 16,7 reales, experimentando unas oscilaciones importantes, desde los 10 reales de 1771 y 1772 a los 24 reales en el año 1769 . Como resumen de todo ello podemos concluir que en el período comprendido entre 1753 y 1778 los precios de los cereales no sufrieron variaciones espectaculares en el Estado de Feria, sino las puramente coyunturales ${ }^{20}$.

\footnotetext{
18 Torras Elías, J., «Sobre la renta señorial en Cataluña a finales del siglo xvill», en La Economia agraria en la Historia de España. Madrid 1978, págs. 324-325.

19 Hamilton, E. J., Guerra y precios en España, 1651-1800. Madrid 1988, pág. 222.

20 Hemos de reseñar la contradicción entre los precios de los cereales declarados por las villas en el catastro de Ensenada con los que cobraban los mayordomos del Duque en
} 
En 1794, los precios medios utilizados por el contador de Zafra para calcular lo producido por las rentas en grano del Estado de Feria en el quinquenio 1790-1794 fueron de 36 reales la fanega de trigo, 19 la cebada, 26 el centeno, 13 la avena, 32 las habas y 61 los garbanzos. Con estos datos podemos plantear como hipótesis de trabajo que los precios de los productos agricolas no crecieron de una manera significativa en el Estado de Feria en el periodo 1753-1794, salvando las diferencias ciclicas y coyunturales que son consustanciales a este tipo de rentas agricolas.

Sin embargo, a finales de siglo se observa una fuerte inflación de los precios, principalmente en los años 1796 y 1797, en los que el trigo se cotiza a 65 reales y a 68 reales y 30 maravedis, respectivamente, con lo que estaba cercano al doble del precio del quinquenio 1790-1794, aunque en 1798 desciende hasta 42 reales y 32 marv. El año 1797 debió ser catastrófico pues la cebada subió hasta 46 reales 29 mrv., más del doble del período antedicho. Y lo mismo se puede decir de los demás productos, pues el centeno se cotizó ese año a 48 reales, la avena a 32 , las habas a 51 y los garbanzos a 91 .

Este periodo ha sido muy bien estudiado por el profesor Gonzalo Anes, quien asegura que las fluctuaciones de los precios de los productos agrícolas a finales del siglo XVIII y comienzos del siglo xIx fueron mucho más violentas que en cualquier otro periodo anterior, y las atribuye a las malas cosechas de estos años ${ }^{21}$. Para los precios de Extremadura el profesor Anes ha manejado datos de los mercados de Cáceres, Plasencia, Alcántar, Trujillo, Badajoz, Villanueva de la Serena y Llerena. Para la comparación con lo sucedido en el Estado de Feria estudiaremos la evolución de los dos mercados extremeños más cercanos: Llerena y Badajoz. En Badajoz los precios del trigo en el ciclo comprendido entre 1793-94 y 1797-98 fueron, 79, 99 reales por fanega en 1793-94, un mínimo de 47, 48 en 1795-96, finalizando con 72,45 reales en 1797-98, el resto de los datos de comienzos del siglo xIX resultan fragmentarios. En Llerena, el precio medio del trigo en $\$ 793-94$ fue de 87,12 reales de vellón por fanega, que se sitúa el máximo en los mercados de Extremadura. El ciclo terminó en 1797-98 con 83,40 reales. El precio mínimo del ciclo fue de 39,5 reales en 1795-96. El precio del año 1804-05 fue de 126,25 reales, que a pesar de ser el más bajo de todos los mercados de la provincia extremeña supuso

\footnotetext{
la misma época. Mientras aquellas incluian precios del trigo de 15 a 16 reales la fanega, los mayordomos los elevaban a más de 30 reales. Una de las razones posibles de la diferencia de precios tan ostensibles es que los empleados del Duque esperarian a los meses de mayor cotización para vender el grano, por ello consideramos éstos como precios máiximos.

21 ANes, G., Las crisis agrarias en la España Moderna. Madrid 1970, pág. 221.
} 
un incremento del 264,89 por 100 con respecto al mínimo del cicio, en 1802-03 que fue de 46,66 reales ${ }^{22}$.

Es bastante difícil establecer comparaciones con los precios del Estado de Feria. En este señorío los precios máximos del trigo en el período 1794-98 aparecen más bajos que en los mercados antedichos, pues la mayor cotización es la ya citada de 68 reales y 30 mrv. en 1797, mientras que en Badajoz y Llerena superaban los 72 y 83 reales, respectivamente. Los minimos del ciclo son más fácilmente comparables, pues en 1795 se vende el trigo en el señorio a 39 r. y $27 \mathrm{mrv}$., mientras que en las dos ciudades citadas alcanzan en $1795-96$ los 47,48 y los 39,5 reales. En los años finales del siglo xVII y los primeros años del XIX, hay mayores coincidencias entre el Estado de Feria y los mercados extremeños citados por el profesor Anes. El año agrícola 1799-1800 parece haber sido especialmente benigno, y donde los precios experimentaron los minimos. En Trujillo se pagó el trigo a 41,16 reales, en Villanueva de la Serena a 34,59 y en Llerena a 37,11 . Mientras que en Oliva y Valencia del Mombuey se vendió por cantidades que se situaban entre 34 y 48 reales. El año más difícil del ciclo fue el de 1804-1805, pues los datos que Anes aporta de los precios en Extremadura señalan unas subidas enormes. Así, en Cáceres se pagaron 162,4 reales por la fanega de trigo, en Plasencia 172,22, en Alcántara 162,35, en Trujillo 185,83, en Villanueva de la Serena 173,12 y en Llerena 128,25 . Todo ello está muy en consonancia con lo ocurrido en el Estado de Feria. Pues según la cuenta general presentada por el ma-

CUADRO 8. PRECIOS MEDIOS DE PRODUCTOS AGRICOLAS EN EL ESTADO

DE FERIA EN EL PERIODO 1795-1798

(reales y marv. von/fanega)

\begin{tabular}{|c|c|c|c|c|c|}
\hline PRODUCTO & 1794 (a) & 1795 & 1796 & 1797 & 1798 \\
\hline Trigo & 36 & $39-27$ & 65 & $68-30$ & $42-32$ \\
\hline Cebada ........................ & 19 & $12-17$ & $34-29$ & $46-28$ & $23-22$ \\
\hline Centeno & 26 & 23 & $35-22$ & 48 & $30-17$ \\
\hline 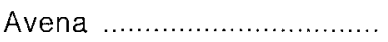 & 13 & $7-25$ & $19-26$ & 32 & $33-5$ \\
\hline Habas & 32 & $26-22$ & 38 & 51 & - \\
\hline Garbanzos .......................... & 61 & 58 & 74- 8 & 91 & $63-11$ \\
\hline
\end{tabular}

(a) los datos de 1794 son precios medios del quinquenio 1790-1794.

Fuente: AHMZ - FDF - C. 53, leg. 2. Rentas Duque 1794, y C. 141, leg. 1. Precios grano 1795-98.

22 Ibidem, págs. 232-236. 
yordomo de Oliva y Valencia, las variedades de trigo temprano y pelón se cotizaron en estas villas en el periodo 1 de agosto 1804 y 31 de julio de 1805 a 120 reales la fanega, mientras la cebada se vendió a 80 , el centeno de 85 a 120, la avena de 34 a 52, las habas a 120 y los garbanzos alcanzaron la increible cifra de 140 a 180 reales la fanega ${ }^{23}$. El año agrícola 1804-1805 resultó catastrófico, pues la subida de precios fue espectacular.

Para el estudio del comportamiento de las rentas de la Casa de Feria en la segunda mitad del siglo XVIII, dividiremos el periodo en dos etapas: 1751-1770 y 1771-1800.

En la primera de ellas los capitulos de renta de mayor importancia eran los dimanantes de los diezmos, primicias, medios terrazgos y novenos de granos, el segundo lugar lo ocupaban las alcabalas y en tercera posición se situaban los arrendamientos de las hierbas de las dehesas. En los años 1751-54 partíamos de unos bajos ingresos. La villa más importante para la contaduría era Zafra, pues aportaba ella sola casi la cuarta parte de las rentas, 72.977 reales para un total de 293.181 , la mayoría procedían de las alcabalas. La segunda población era Santa Marta con el 15,9 por 100 de los ingresos, 46.722 reales, cuya mayor parte la integraban los 37.483 reales de los novenos de granos que pagaban los agricultores que cultivaban las tierras novenarias. En Oliva se recaudaban 46.423 reales, el 15,8 por 100 de las rentas, principalmente de tres conceptos: las dehesas del Campo, Monturque, Matilla y Marihernández arrendadas al Común de vecinos de la villa por 13.000 reales, y los diezmos de granos y los diezmos de lechones, que se contabilizaban en Oliva unidos los de esta villa y los de Valencia del Mombuey. En Villalba se conseguía el 13,5 por 100 , de las cuales los novenos de granos suponian 23.959 reales. Las dehesas de Salvaleón, denominadas Bejarana y Palacio, colocaban a esta villa en el quinto lugar de los ingresos con el 12,2 por 100 , mientras que en Nogales, la dehesa de Santa Justa, los novenos y los rastrojos conseguian el 8,3 por 100 de las rentas totales. Las demás villas no conseguian dotar a la contaduría de ingresos dignos de mención.

Los datos fragmentarios de los que disponemos no nos permiten emitir un juicio exacto de lo acontecido en el quinquenio 1755-60, y en el siguiente de 1761-1765 la situación había cambiado de una manera significativa, pues la escasa recaudación de las alcabalas de Zafra de los años 1763 y 1764 y la nula de 1765 propiciaron la sensible caida porcentual de los ingresos hasta situarlos en el 12,4 por 100 , pasando al cuarto

${ }^{23}$ AHMZ, F.D.F., Carp. 13, leg. 65. Cuenta Oliva, 1805. 
lugar entre las villas del Estado de Feria. Esto, a su vez, hizo descerider la importancia relativa de los ingresos de las alcabalas e incrementó la de los granos, mientras que los producidos por las hierbas de las dehesas se mantenian en un discreto tercer lugar. Con la reforma administrativa Ilevada a cabo por la contaduría del Estado de Feria, suprimiendo las mayordomias de Nogales y Solana, se potenció la importancia de las de Santa Marta y Villalba, pues a partir de 1864 Santa Marta comenzó a contabilizar la recaudación de los granos de Nogales y Corte de Peleas, mientras que Villalba hacía lo propio en relación al grano de Solana. Por ello en el quinquenio 1761-65 Santa Marta se situaba en primer lugar de las villas por su recaudación con 114.144 reales, 27,8 por 100 , de los que 105.870 procedian de los novenos de granos. Villalba ascendió a segundo lugar con 77.985 reales, el 19 por 100 , de los cuales 58.131 eran rentas de granos. Mientras Oliva, aunque descendía en su porcentaje hasta el 13,4 por 100 , también superaba a Zafra con 55.126 reales.

Los ingresos de granos, que procedian de los novenos de granos del marquesado y de Nogales, así como de los diezmos de Oliva y Valencia del Mombuey incrementaron su importancia hasta lograr representar el 47,6 por 100 de todos los ingresos, mientras que las alcabalas pasaban al 18,8 por 100 y las dehesas al 18,25 .

Aunque las dehesas no habian logrado en esos momentos el peso económico que tendríar, después, es necesario detenernos, aunque sea brevemente para establecer algunas consideraciones en relación a estos precios. Ya en una fecha tan temprana como 1742, recien asumido el control económico por parte del Duque, después del periodo de concurso de sus rentas, la contaduría del Estado de Feria emitió un amplio y documentado informe de la situación de cada una de las dehesas del Estado, especificando el arriendo que se cobraba por ellas, la capacidad ganadera de sus hierbas y bellotas y la posibilidad de incremento de sus rentas desde 82.778 hasta 110.650 reales.

La adquisición de las dehesas del Redrojo y del Rincón de Almorchón no produjo un incremento inmediato de la importancia de este capítulo de rentas, proque el duque de Medinaceli poseia una importante cabaña ganadera de ovejas merinas que invernaban en las dehesas del Estado de Feria. Nos consta que en la invernada del año 1765 al 1766 aprovecharon las hierbas de las dehesas del Redrojo, Santa Justa Maricara y Entrines, Salamanco, Atalaya, Bravero y la del Rincón de Almorchón, y esto detraía ingresos contabilizados en una cifra de 42.233 reales ${ }^{24}$.

${ }^{24} \mathrm{AHMZ}$, FDF, leg. 0101. Cuentas generales, 23952 a 24004. Cuenta de los gastos causados por la cabaña del Excelentísimo señor duque de Medinaceli este invernadero de 65 a 66 . 
En el periodo 1761-65, a pesar del descenso de alcabalas y la poca importancia de las dehesas, las rentas medias del Estado crecieron de 293.181 a los 410.427 reales de vellón.

En el quinquenio 1765-1770 no se aprecian cambios drásticos en todo lo comentado, únicamente que las alcabalas de Zafra recobraron su peso económico hasta situarse en 73.527 reales de media, subiendo esta villa hasta el segundo lugar, mientras que Santa Marta descendia al tercero por el discreto comportamiento de los ingresos de granos, mientras que Villalba sin embargo se elevaba al primer lugar. Los capítulos de rentas permanecian en las mismas posiciones anteriores. A la primera etapa de 1751 a 1770 podemos calificarla de transición entre una economia intervenida por la monarquia a través del concurso de las rentas, y una toma de contacto por parte del contador del Estado de Feria, que intenta obtener de los pueblos los mayores beneficios sin lograrlo aún, debido a las dificultades y a la necesidad de una reforma administrativa, que aunque se llevó a cabo en los años 1760, no acababa de dar los resultados apetecidos. La segunda etapa, 1771-1800, resulta muy interesante por los cambios tan trascendentales que se advierten en la evolución de las rentas. Desde 1770 a 1780 acontece el mayor de los incrementos globales y la más drástica transformación cualitativa de las rentas. Ya en el primer quinquenio, 1771-1775, se nos anuncia lo que se confirmará posteriormente, pues crecieron hasta un valor medio anual de 426.063 reales. Los ingresos de los novenos y diezmos de granos tuvieron un comportamiento discreto, 96.719 reales, el 22, 7 por 100, las alcabalas se mantuvieron estables en 98.026 reales y el 23 por 100 y lo más significativo fue la evolución de las dehesas, pues mientras que en el anterior quinquenio produjeron apenas 85.000 reales, en $1771-1775$ Ilegaron a 167.957 reales. Hemos de reconocer que en parte acontece por una dificultad de conocer sus rentas en los periodos anteriores, pero en su mayoría se produjo por la politica de la Contaduría Mayor del Ducado de obtener el mayor provecho de sus hierbas, prefiriendo arrendarla a los ganaderos trashumantes mesteños en detrimiento de los vecinos de los pueblos. Ese comportamiento creará tensiones, pero aportará pingües beneficios al Duque.

El quinquenio 1776-1780 confirmaba la tendencia alcista en las rentas de las dehesas que llegába hasta los 192.250 reales anuales, el 33,2 por 100 de las rentas, aunque en esta ocasión los ingresos de novenos y diezmos de granos les superaban al alcanzar los 210.449 reales, el 36 por 100. Las dehesas se mostrarán, a partir de estos momentos, como unas rentas más seguras y menos influidas por las inclemencias climáticas. Las alcabalas aparecian muy estables, consiguiéndose con ellas 102.970 reales, el 17,8 por 100. Las rentas medias anuales del quinquenio, alcanzaron la cifra más elevada hasta el momento: 577.358 reales de vellón. 
El comportamiento de las rentas del Estado de Feria desde 1770 a 1780 fue muy favorable pues los datos que disponemos nos aseguran un incremento de 48,7 por 100 , bien es verdad que todavía ignoramos las rentas de algunas dehesas en períodos anteriores, lo cual posiblemente reduciría algo esa cifra. Pero el crecimiento de los ingresos de la hacienda ducal coincide con lo escrito por Pierre Vilar, quien en su obra Catalunya dins l'Espanya moderna estudia once series de ingresos señoriales del patrimonio Real y nos informa que los años que median entre 1760 y 1780 fue el mejor período del siglo para los ingresos señoriales ${ }^{25}$. Jaume Torrás argumenta que lo más sustancial del incremento de rentas habia sucedido en los dos primeros tercios del siglo xVIII, cuando los señores pudieron beneficiarse a la vez del alza de los precios y de la expansión agrícola $^{26}$.

En el Estado de Feria los quinquenios 1781-1785, 1786-1790 y 1791-1795 mantuvieron las rentas medias anuales de una manera constante en torno a los 500.000 reales. Continuaron creciendo los ingresos de las dehesas desde los 206.391 reales de $1781-85$ hasta los 236.797 de $1791-95$, adquiriendo paulatinamente mayor porcentaje en los totales, 41,8, 42,6 y 47,7, respectivamente. Los novenos y diezmos de granos pasaron del 22,5 al 25,5 y al 18,6 , y las alcabalas continuaron invariables en torno al 21 por 100. Los novenos y diezmos de ganado durante todo el período de 1751 a 1791 permanecieron en el 8 por 100.

Precisamente, este auge de las rentas de las dehesas desplazó el centro de gravedad de las rentas ducales hacia las que calificamos como "otras rentas", donde se insertaban varias de las dehesas más productivas: las de Monturgue, Matilla y Marihernández, la del Redrojo y la del Rincón de Almorchón. Estas rentas supusieron el 19,7, 19,9 y 21,1 por 100, respectivamente, en los tres quinquenios. Mientras que en Zafra se recaudaba en torno al 16 por 100 y en Oliva de la Frontera el 14,7, el 18,8 y el 12,9 y Villalba y Santa Marta perdían importancia para situarse en algo más del 10 por 100 cada una en el quinquenio 1791-1795.

La creciente evolución de los arriendos de las hierbas de las dehesas del Estado de Feria justifica que nos detengamos a hacer algunas consideraciones. En los años finales del siglo xvIII el duque de Medinaceli era dueño de un buen número de dehesas en Extramadura: la del Campo en Oliva, Bravero en Valencia del Mombuey, Atalaya y Yeguas en Santa Marta, Santa Justa, Maricara, Entrín del Medio y Entrín Bajero en Noga-

\footnotetext{
${ }^{25}$ VILAR, P., Op. cit, pág. 537.

26 Torras Elías, J., Art. cit., pág. 323-328.
} 
les, Palacio y Bejarana en Salvaleón, Salamanco en la Parra, todas ellas en el Estado de Feria; Monturque, Matilla y Marihernández en Jerez de los Caballeros, Rincón de Almorchón en Cabeza del Buey y Redrojo en Rivera del Fresno, ubicadas éstas fuera del ámbito jurisdiccional antedicho. Todas eran de pasto, labor y bellota, pero la mayor fuente de ingresos para el Estado de Feria consistía en el arrendamiento de los pastos para el ganado ovino.

Enrique Llopis Agelán, en su estudio de la cabaña del monasterio de Guadalupe en el período 1709-1835, ha llegado a la conclusión de que durante la primera mitad del siglo xVIII el abaratamiento de las hierbas extremeñas con respecto a los obtenido por la venta de lana fue considerable, y asi de las 10,72 merinas que podian sustentarse durante el otoño e invierno con el importe de una arroba de lana fina en 1709-1710 se pasó a las 17,8 en 1728-1730, lo que suponía un incremento del 66,04 por ciento. Si tenemos en cuenta que los pastos de invernada alcanzaban el 35 por ciento de los costes de producción de las cabañas, este cambio en los precios debió incidir en el crecimiento de los beneficios de los ganaderos mesteños ${ }^{27}$. Es lógico, por tanto, que la hacienda desease participar de este buen momento, incrementando el arridendo de las dehesas. En la segunda mitad del siglo XVIII se procuró arrendárselas a los ganaderos trashumantes de la mesra, aunque fuera a costa de arrebatar a los pueblos una de sus fuentes de riqueza más importantes. En Oliva de la Frontera el Común de vecinos habia arrendado al Duque tradicionalmente las hierbas de invernadero de la dehesa del Campo y las de Monturque, Matilla y Marihernández por 13.000 reales cada temporada. Después de una dura lucha el señor jurisdiccional logró elevar el arriendo de la dehesa del Campo a 28.000 reales y hacer un contrato de las otras con un ganadero trashumante. Los vecinos de Valencia del Mombuey y de Rivera del Fresno vieron cómo el Duque también arrendaba las dehesas del Bravero y del Redrojo a un trashumante riojano llamado don Joaquín López Montenegro. Este mesteño arrendó, a partir de 1775, las hierbas de agostadero e invernadero de las dehesas de Salamanco en la Parra, Santa Justa, Maricara, Entrin del Medio y Entrin Bajero en Nogales, y las hierbas de invernadero de las de Atalaya en Santa Marta, Bravero en Valencia del Mombuey, y un millar de la dehesa del Rincón de Almorchón en Cabeza del Buey; y a partir del 29 de septiembre de 1776 las hierbas de invernadero y agostadero de la del Redrojo en Rivera del Fres-

\footnotetext{
27 LLoPIS Agelan, E., "Las explotaciones trashumantes en el siglo xvm y primer tercio de xIx: La cabaña del Monasterio de Guadalupe, 1709-1835", en La economía española al final del Antiguo Régimen, I. Agricultura. Madrid 1982, pág. 29-31.
} 
no. Además, y como una muestra del acaparamiento del riojano, desde el arriendo de 1781-85 incluyó en él las bellotas de las dehesas de Santa Justa y de Salamanco. Los arrendamientos se firmaban en Madrid, y las gestiones se llevaban a cabo en la Contaduría Mayor del ducado de Medinaceli, de tal forma que los arriendos no aparecian en las cuentas generales de la contaduría del Estado de Feria.

En la escritura de arriendo se especificaban claramente las condiciones:

- El arriendo era por un espacio de tiempo de tres, cuatro, seis o nueve años y comenzaba a contarse desde el 29 de septiembre, día de San Miguel y se hacía constar que las dehesas de Santa Justa, Maricara, Entrín Somero y Entrín Bajero del término de Nogales solamente eran de labor por año y vez, de modo que los rastrojos habian de quedar libres para pastos, sin poderse sembrar sobre ellos hasta pasado un año después de alzado el fruto.

- El pago de cada uno de los años del arriendo se haria en dos plazos que vencían el 25 de diciembre y el 25 de marzo siguiente, concretándose la cantidad a entregar en moneda de oro y plata corriente. En caso de que el ganadero dejase de pagar el arriendo, se le podía apremiar con todo el rigor por vía ejecutiva con el solo documento de la escritura.

- Si el Duque necesitase el Entrín Bajero para que lo aprovechasen los ganados propios lo pudiera hacer.

- Don Joaquin López Montenegro renunciaba al derecho y privilegio de tasa, y en caso de desear valerse de dicho priviligeio no se le admitiese recurso en tribunal alguno para ese asunto.

- Para mayor seguridad del pago y cumplimiento de esa escritura, el ganadero se obligaba a dejar hipotecados todos los frutos y ganados mayores y menores que entrasen en las dehesas hasta haber satisfecho enteramente la renta.

- El arrendamiento se hacía a riesgo y ventura del ganadero, no siendo motivo para reducción de las cantidades a pagar el hecho de que hubiese escasez de aguas y de hierbas, ni otros desastres o plagas como langosta o pedrisco.

Don Joaquín López Montenegro se comprometía a cuidar con esmero y a criar, durante todo el tiempo que durase el contrato, los numerosos chaparros que había en la dehesa del Redrojo, así como a la conservación, guarda y aumento del referido monte. 
- La defensa ante los pleitos de cualquier clase que se suscitasen sería por cuenta del ganadero.

- El arrendatario no podria subarrendar ni el todo ni parte de la dehesa del Redrojo a los mesteños ni a otras personas que poseyesen idénticos privilegios.

- Quedaban a cuenta del arrendatario los gastos que produjese la cobranza del arrendamiento $y$ el documento de escritura de arriendo ${ }^{28}$.

Desde 1775 a 1802, período del que tenemos información completa, se arrendaron estas dehesas en seis ocasiones sucesivamente. Los primeros plazos de arriendo eran de tres años, 1775-1778 y 1778-1781; los dos siguientes de cuatro años, $1781-1785$ y 1785-1789. El posterior plazo fue de 1789 a 1795, pero por el fallecimiento del arrendatario hubo de renovarse con los hijos en 1793, momento en que se decidió hacerlo en un plazo de nueve años hasta 1802. Los precios de arriendo se mantuvieron constantes desde 1775 a 1781 en 76.990 reales, se incrementaron en 1781 a 87.388 y en 1785 a 90.000 reales. En 1789 se aumentaron hasta 93.000 reales, que era el mismo arriendo del período 1793-1802. Aunque los incrementos no fueron muy importantes, las cantidades globales adquirieron gran significación. En lo que se refiere a otras dehesas, la del Rincón de Almorchón se arrendó durante un periodo de tiempo al marqués de Yranda por 46.283 reales al año. El sistema de arrendamiento fue beneficioso para ambas partes contratantes. Para el ganadero, porque con una renta a largo plazo se aseguraban buenos pastos para su ganado a un precio razonable, y para el Duque porque, apenas sin gastos de administración, recibia cantidades importantes de dinero, y la solvencia de los grandes arrendatarios le daba la seguridad de la percepción de las rentas con absoluta puntualidad.

Las rentas del Estado de Feria crecieron en el último quinquenio del siglo hasta los 641.377 reales, por un comportamiento excelente de los ingresos de granos que suponian cifras de 200.000 reales debido a los elevados precios en un momento extraordinariamente inflacionista. Las dehesas sufrieron un ligero descenso hasta los 226.868 reales y las alcabalas crecieron ligeramente logrando 116.149 reales de renta anual media, aunque bajaron en su importancia global hasta el 18,1 por 100 .

28 AHMZ, FDF, leg. Escritura de Arrendamiento de nueve dehesas en Extremadura, otorgada por Exm. Sr. Duque de Medinaceli a favor de D. Josef Joaquín López Montenegro, ganadero trashumante por tiempo de seis años y noventa y tres mil reales cada uno, 14 agosto 1789 . 
Las rentas del ducado de Feria en la segunda mitad del siglo xvIII

CUAdRO 9. DÉBITOS AL ESTADO DE FERIA EN LA SEGUNDA MITAD DEL. SIGLO XVIII

(en reales de vellón)

\begin{tabular}{rrrr}
\hline AÑOS & DEBITOS & ANOS & DÉBITOS \\
\hline 1762 & 151.197 & 1782 & 200.006 \\
1763 & 150.232 & 1783 & 162.414 \\
1764 & 135.803 & 1784 & 98.635 \\
1765 & 176.823 & 1785 & 75.548 \\
1768 & 145.612 & 1786 & 53.036 \\
1769 & 168.147 & 1787 & 65.919 \\
1770 & 104.033 & 1788 & 56.289 \\
1771 & 123.574 & 1790 & 26.381 \\
1772 & 147.562 & 1791 & 90.053 \\
1773 & 202.076 & 1792 & 119.813 \\
1774 & 185.085 & 1793 & 120.786 \\
1775 & 229.202 & 1794 & 111.807 \\
1776 & 188.044 & 1795 & 141.785 \\
1777 & 164.711 & 1796 & 186.167 \\
1778 & 222.736 & 1797 & 254.177 \\
1779 & 276.645 & 1798 & 297.873 \\
1780 & 284.488 & 1799 & 312.058 \\
1781 & 228.687 & 1800 & 358.288 \\
\hline
\end{tabular}

Fuente: AHMZ - FDF, leg. 0101. Cuentas generales del Estado de Feria en el periodo $1762-1800$.

El panorama tan halagüeño que presentaban las rentas del Estado de Feria en la época finisecular se vería empañado por el problema de los impagados. El hecho de que el contador anotase en la cuenta general de cada año las rentas que el Estado de Feria tenía derecho a cobrar en cada uno de los pueblos enmascaraba un poco la situación, pues consultadas solas las cifras pueden dar lugar a una interpretación de la situación más favorable que la situación real. La verdad es que durante muchos años las cif́ras de impagados no fueron alarmantes y se mantenian en unos tonos razonables. En el cuadro de débitos vemos que la década de los años 60 finaliza con 104.033 reales no cobrados hasta el año 1770 , cifra favorable si consideramos que en 1762 eran 151.197 reales. La década siguiente finalizó con 284.488 reales de débitos, que se podría considerar preocupante, pero la estupenda evolución en la década de los años 80 solucionó esta desfavorable circunstancia, pues en 1790 los impagados solamente eran 26.381 reales y ello presagiaba un final de siglo extraordinariamente fructífero. Sin embargo, la última década del 
siglo XVIII resultó muy problemática para las arcas de la hacienda señorial, pues en 1795 las rentas no cobradas era de 141.785 reales, y la tendencia era a la acumulación rápida de los débitos, de tal forma que en 1800 se habian elevado hasta los 358.288 reales.

\section{LOS GASTOS Y EL BALANCE ECONÓMICO}

En la segunda mitad del siglo XVIII, aunque el duque de Medinaceli habia logrado recuperar el control de las rentas de sus estados, no se había visto libre de los problemas de endeudamiento, como tendremos ocasión de comprobar. Pero hemos de separar lo que eran problemas económicos de la familia señorial, de la rentabilidad que producian los bienes del Estado de Feria. Lo que parece surgir de la documentación consultada es que el Estado de Feria era rentable económicamente, pero eran muy cuantiosas las cargas que el duque de Medinaceli, como titular del Estado de Feria, había de soportar a mediados del siglo xvIII, consumiendo una parte muy sustanciosas de las rentas. Nos ha sido difícil averiguar el destino de estos dineros, pues los contadores no eran tan explicitos como en los ingresos y en la mayoria de los casos se limitaban a asentar en la cuenta anual los gastos de cada mes sin especificar su destino. Por ello hemos analizado detenidamente las ocasiones en las que se han mostrado más dispuestos a especificarlos. Concretamente en la cuenta de 1753 el tesorero don Pedro de la Concha incluye una pormenorizada lista de todos los pagos realizados en ese año ${ }^{29}$. Hemos clasificado los gastos en: censos, sueldos de empleados, situados de curas y sacristanes, gastos de pleitos y de contaduria.

Lo que más nos llama la atención es que los réditos de los censos suponen más de la mitad de los gastos del Estado de Feria a mediados del siglo XVIII, con un 52,7 por 100 . Se trataba de 57 censos, que aunque de escasa cuantía, considerados individualmente, suponian un montante total de 74.894 reales. Sus réditos se pagaban en su mayor parte a obras religiosas o asistenciales: capellanias, hospitales, conventos e iglesias. Con lo cual se ponen de manifiesto dos cuestiones importantes: la función crediticia de la Iglesia en la economia del Antiguo Régimen, y la necesidad de la nobleza de recurrir a los censos para resolver su problema de liquidez económica. Los réditos más cuantiosos que se pagaban por el

${ }^{29}$ AHMZ, FDF, leg. 0101, folios 1942-2029. Cuenta general de 1753. 
Estado de Feria eran 5.878 reales al convento de religiosas de Santa Marina, 5.387 a la cofradía de la Santa Caridad, 5.294 al mayorazgo que fundó Juan Ramírez el Viejo, 5.111 al convento de Santa Catalina, 4.319 a la iglesia colegial, y 3.831 reales al convento de Santa Clara; todos ellos ubicados en Zafra.

La segunda partida de gastos es la de pleitos y de Contaduria, suponiendo el 29,5 por 100, con un montante de 41.969 reales. De ellos se pagaron 19.166 reales en la probanza de un pleito contra Oliva, que demuestra la gran conflictividad de esta villa.

Los sueldos de empleados solamente totalizaban 18.866 reales (el 13,2 por 100), entre ellos destacaban los 4.411 reales y 26 mrvs. pagados al contador y al tesorero, los 3.308 al oficial mayor, 2.647 al gobernador del Estado y 2.205 reales al oficial segundo. El resto de los emolumentos de empleados son de escasa importancia.

La partida de menor entidad era la que denominamos de gastos decimales. Consecuencia de la percepción de los diezmos en algunos lugares del Estado de Feria, el Duque tenía adquiridas obligaciones decimales con la Iglesia en las villas de Oliva, Valencia de Mombuey, Solana y Corte de Peleas. Concretamente el sostenimiento de las parroquias, con el pago de las reparaciones de las iglesias y la adquisición de los objetos de culto y el abono de los sueldos a curas y sacristanes. En total eran 6.306 reales $(4,4$ por 100$)$.

El contador, en un informe al Duque sobre las rentas del Estado de Feria en los años 1788 y 1789 a efectos de la contribución de los frutos

CUADRO 10. GASTOS DEL ESTADO DE FERIA A MEDIADOS DEL SIGLO XVIII, AÑO 1753

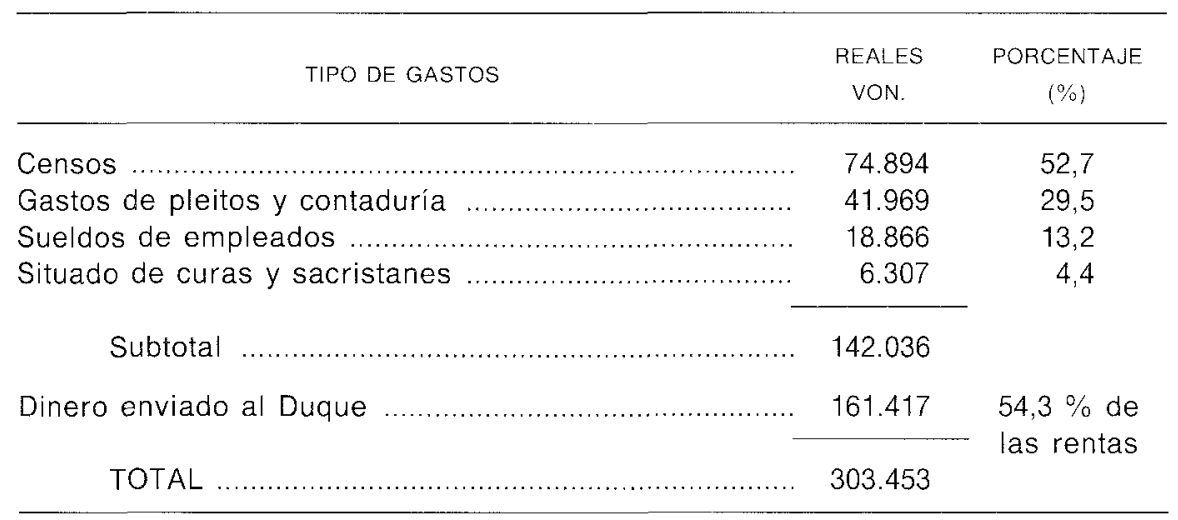

Fuente: AHMZ-FDF 0101, folios 1942-2029. Cuenta general del año 1753. 
civiles, calculaba unos ingresos de 419.712 y 412.017 reales respectivamente, sin incluir las rentas en grano. Diferenciaba dos partidas de gastos. La primera, formada por los réditos de censos, repartidos entre obras eclesiásticas, manos muertas y seglares. Se llegaba a la astronómica cifra de 225.900 reales. Comparándolas con la de 1753, llegamos a la evidencia de que el ducado tenia que abonar en esos momentos 151.006 reales más. Por tanto existia un progresivo endeudamiento del Duque, que se veía obligado a suscribir censos con entidades eclesiásticas, e hipotecarse paulatinamente. De entre todos los cerisos destacaban dos de enorme importancia, el pago de 120.000 y 71.071 reales de réditos de dos censos a la obra pía de los Santos Lugares de Jerusalén, en Madrid, Io cual sumaba 191.071 reales en total. El resto de los veintiún censos era de menor entidad, e incluso algunos debian haber sido redimidos, pues apenas dos vínculos, un mayorazgo y un censo de la iglesia colegial de Zafra superaban los 5.000 reales. La segunda partida era la de gastos decimales, por lo pagado a curas y sacristanes y al cabildo de la iglesia de Badajoz, que totalizaba 11.107 reales en metálico y 110 fanegas de trigo y 30 de cebada ${ }^{30}$. En total los gastos de cada uno de estos años -1788 y 1789 - eran de 237.005 reales, a los que había que añadir los sueldos de empleados, los gastos de contaduría, etc.

Tomando como referencia la declaración para la liquidación de la contribución extraordinaria, que hizo el contador de Zafra en 1795, comprobaremos que los gastos del Estado de Feria se habian incrementado al compás de los ingresos y suponían en esos momentos 248.321 reales.

\section{CUADRO 11. GASTOS DEL ESTADO DE FERIA EN 1795}

\begin{tabular}{|c|c|c|}
\hline TIPO DE GASTOS & $\begin{array}{c}\text { REALES } \\
\text { VON. }\end{array}$ & $\begin{array}{c}\text { PORCENTAJE } \\
(\%)\end{array}$ \\
\hline Censos de iglesias y obras pías & 209.591 & 84,4 \\
\hline Censos en favor de seglares ..... & 15.167 & 6,1 \\
\hline Gastos decimales ..................... & 16.797 & 6,7 \\
\hline Cargas de patronatos ............. & 1.443 & 0,5 \\
\hline Otros gastos ............... & 5.323 & 2,1 \\
\hline TOTAL .............. & 248.321 & \\
\hline
\end{tabular}

Fuente: AHMZ-FDF, C. 68, leg. 2. Relación de rentas y cargas para liquidación de contribución extraord. 1795.

3) AHMZ, FDF, carp. 141, Ig. 1. El contador para cumplir orden 11 de junio de 1787 sobre: contribución frutos civiles 
Siguiendo el criterio del contador, los agruparemos en: censos, gastos decimales, de patronatos y otros.

El capítulo más voluminoso seguía correspondiendo a los censos, desglosados en dos subcapítulos: los que se abonaban en favor de iglesias y obras pias - 84,4 por 100- y los censos a favor de seglares - 6,1 por 100 - El caso más gravoso continuaban siendo los réditos de dos censos de la obra pía de los Santos lugares de Jerusalén, que en 1795 percibia 191.071 reales, el 77 por 100 de todos los cargos que se deducian en la contribución de frutos civiles. Esta obra pía obtenia para sí la tercera parte de todas las rentas brutas del Estado de Feria. El resto de los gastos perdian importancia ante esta "sangría» de dinero.

Los gastos decimales se incrementaron en 1795 hasta alcanzar la cifra de 16.797 reales, el 6,7 por 100 . Los de patronato incluian solamente pequeñas ayudas a los conventos de Santo Domingo del Campo y al de San Benito. En el capitulo de «otros» destaca el sueldo del gobernador de Zafra, que cobraba 2.647 reales y 40 fanegas de trigo al año.

Además de estos gastos hemos de referirnos a otros no incluidos en la relación de 1795. Sabemos que el Duque en 1798 hubo de desembolsar para sueldos de empleados 82.788 reales, que sumados a los comentados resultan 331.109 , a los que añadimos los sueldos a viudas, huérfanos, canónicos de la Colegial de Zafra, etc., todo lo cual sobrepasaría los 380.000 reales al año, y por tanto quedarian unos 190.000 reales de renta liquida. Como queremos basar nuestros cálculos en datos muy exactos cuantitativamente, hemos de recurrir a los planes generales de las rentas del Estado de Feria que se conservan de esta época, concretamente de 17891793 y de 1798-1802. En ellos se especificaban los ingresos de la Contaduria de Zafra, y los de cada una de las tres mayordomías: Santa Marta, Villalba y Oliva. Aparecen también los gastos, lo que nos permite conocer el producto líquido ${ }^{31}$.

Los resultados del quinquenio 1739-1793 fueron:

2.109.516 reales de ingresos, a los que había que añadir los 143.000 anuales que producian los arrendamientos de las dehesas, que por abonarse en Madrid no se incluian en las cuentas —eran 715.000 al quinque-

\footnotetext{
${ }^{31}$ Una cuestión previa antes de pasar a analizar las cifras de los planes generales es que no se reflejan en los ingresos lo abonado por los ganaderos trashumantes que arrendaban las dehesas, pues los contratos y pagos se realizaban en la Contaduría Mayor del Duque en Madrid. Tampoco se hacia en los gastos lo pagado a la obra pia de los Santos Lugares de Jerusalén, pues, del mismo modo, era la Contaduría Mayor la encargada de abonarlos.
} 
nio-, con todo ello se llegaba a 2.824 .516 , que suponían 564.903 reales al año.

821.092 reales de gastos, que unidos a los 199.012 anuales de los censos pagados en Madrid, elevaban la cifra a 1.816.152, es decir 363.230 reales al año.

Quedaban 1.008.364 reales de renta liquida al quinquenio, 201.672 al aก̃o.

Los datos del quinquenio 1798-1802 resultaron ser:

2.743 .738 reales de ingresos brutos, más 104.000 al año de lo producido por las dehesas no contabilizadas en Zafra, resultaban 3.263.738 reales, 652.747 reales.

1.474.550 reales de gastos, que añadidos los censos abonados en Madrid eran 2.469.610, con lo cual se elevaban a 493.922 reales al año.

Sumaban 794.128 reales de renta liquida al quinquenio, y 158.825 reales al año.

En los años finales del siglo xvill y comienzos del siglo xIx, se produjo un descenso de las rentas liquidas del Estado de Feria respecto al quinquenio 1789-1793. La causa no fue el mal comportamiento de los ingresos, sino al contrario, pues aumentaron en el quinquenio 1798-1802, posiblemente debido al incremento de los precios del grano. El motivo principal era el excesivo crecimiento de los gastos en las partidas de los censos, salarios, situados y pleitos, además de la inserción de otras -limosnas, carruajes y botica- no especificadas antes. Los réditos de los censos continuaban siendo a finales del siglo xvIII un auténtico «cáncer» de la economía ducal, pues en el quinquenio 1789-1793 se dedicó a su pago nada menos que el 40,5 por 100 de todos los ingresos brutos. En el quinquenio 1798-1802, a pesar de que hubo un incremento anual de ingresos de 87.844 reales, también aumentaron los réditos de censos hasta los 258.504 reales, y supusieron el 39,6 por 100 de todas las rentas.

En resumen los gastos de censos se dispararon y absorbieron las cuantiosas rentas, y el Duque apenas percibia 150.000 reales al año de estos Estados, que es posible le fueran insuficientes, máxime si tenemos en cuenta que no todas las rentas se cobraban puntualmente. En efecto, recordemos que a partir de 1795 se produjo una rápida subida de los débitos, y el Duque dejó de percibir una parte muy importante de sus ingresos. Al final del siglo los impagados suponian una fuerte rémora para la economía ducal, superior a los 300.000 reales. El incremento de los gastos y las dificultades para cobrar las rentas, a pesar de ser éstas cuantiosas, redujeron de una manera significativa los ingresos netos en las arcas del Estado de Feria a finales del siglo xVIII. La situación eco- 
Las rentas del ducado de Feria en la segunda mitad del siglo xvil

nómica del Duque era precaria, y sus deudas cuantiosas, sin posibilidades de ser saldadas con ingresos ordinarios.

Atienza Hernández asegura que los préstamos obtenidos por los nobles en el siglo xvIII no fueron sólo en forma de hipotecas, censos consignativos y obligaciones, sino también del tipo que denomina uprivado y personal» que suponian simples pagarés firmados por los miembros de la casa nobiliaria para salir de un apuro económico y que era la expresión de una situación de dificultad muy acusada ${ }^{32}$. Como ejemplo de esta deuda "privada" en 1793, D. Luis Fernández de Córdoba, duque de Medinaceli, debía al conde de Goyeneche la cantidad de 3.148.164 reales, importe de dos escrituras de fianza otorgadas en 1789 y 1791 en Madrid. El conde recurrió a la justicia para cobrar la deuda y el alcalde de Casa y Corte D. Gutierre Vaca de Guzmán, ordenó que se le secuestraran al duque de Medinaceli las rentas de sus Estados de Comares, de Priego y de Villalba. En lo que respecta al marquesado de Villalba, en mayo de 1793 se llevó a efecto la evaluación judicial de sus rentas ${ }^{33}$. Pero no cesaron aqui las dificultades económicas de la casa ducal de Medinaceli. Las deudas eran extraordinariamente cuantiosas, y sumaban a finales del siglo XVIII nada menos que 13 millones de reales. El Consejo de Castilla, ante los requerimientos de los acreedores, nombró a D. Benito Puente Juez Comisionado para la enajenación de fincas de los Estados del Duque, en cantidad suficiente para el pago de la deuda. Las más atractivas eran, sin duda, las dehesas, pues su alta rentabilidad les daba la seguridad de ser vendidas en un plazo razonable. De esta forma hay que entender la venta en 1797 de la dehesa del Redrojo, y en 1798 de las de Monturque, Matilla y Marihernández. El problema era que precisamente esta clase de predios lograba los más saneados ingresos para la Casa de Feria, y que en los momentos de su venta ascendian a 31.500 y 11.500 reales respectivamente ${ }^{34}$.

Todo lo que llevamos dicho hasta ahora nos permite hacer un balance de las rentas del Estado de Feria en ia segunda mitad del siglo xvill. Evidentemente, se produjo un incremento en los ingresos desde 1751-1754 hasta 1796-1800. Partiendo del índice 100 en el primero de ellos se llega al 218,7 a final de siglo. El crecimiento resultó mucho más dinámico en el periodo 1771-1780 en el que se partió del indice 132,4 y se llegó al 196.

\footnotetext{
32. Atienza hernández, I., Op. cit., pág. 348.

${ }^{33}$ AHMZ, FDF carp. 144, leg. 15. Dilig. secuestro de rentas del Duque en Marquesado de Villalba, 1793.

${ }^{34}$ AHMZ, FDF, leg. 03-14- Expediente sobre posesión de la dehesa de Monturque, 1779.
} 
Después de un estancamiento bastante prolongado en el período 1781-95, se volvió a acelerar de manera notable en 1796-1800.

El comportamiento favorable de los ingresos ducales causó un proceso de transformación interna en la cualidad de cada capítulo de rentas. Durante los veinte primeros años del periodo, en la etapa de 1751-1770, las rentas de novenos y diezmos de grano ocuparon el primer lugar en los ingresos, únicamente superados en 1751-54 por las alcabalas. Éstas ocuparon el segundo lugar y relegaron a un tercero a los arriendos de las dehesas. Desde 1771 hasta final de siglo se produjo una evolución imparable. Las rentas que producian los arriendos de las hierbas de las dehesas fueron incrementándose de una manera significativa comenzando con 167.957 reales en $1771-75$ para llegar a los 236.797 reales en 1791 95 adquiriendo el primer lugar entre los capitulos de renta, puesto que no perderia en ningún momento de esta etapa. El fenómeno de auge se desarrolló gracias a la adquisición de dos nuevas dehesas y a la subida del precio de los pastos. Las rentas en grano siguieron una orientación más irregular pues dependian de la coyuntura de los años agricolas y de la evolución de los precios del trigo; los momentos más dificiles fueron 177175 , y 1791-95 pues no se llegó a los 100.000 reales de venta de grano al año y los más álgidos resultaron 1776-80 y 1796-1800 que superaron los 200.000 reales. Las alcabalas se mostraron muy constantes con 98.000 reales en 1771-75, y creciendo lentamente hasta los 116.149 a final de siglo; ocuparon el tercer lugar entre los capítulos de ingresos, excepto en los momentos en que las desfavorables coyunturas agricolas las aupaban hásta el segundo puesto.

El curso favorable de los arriendos de las dehesas a lo largo de la segunda mitad de siglo tuvo dos consecuencias importantes:

- La tendencia a arrendar grupos de estos precios a ganaderos trashumantes, en detrimento de pequeños arrendatarios y de los concejos de los pueblos donde estaban ubicadas. Esta decisión produjo graves tensiones sociales, en un momento de aumento de demanda de tierra y de pastos por un progresivo crecimiento demográfico.

- El hecho de que los contratos de arrendamientos de las dehesas se firmasen en Madrid, detrajo sus rentas del control y gestión de la contaduría de Zafra, y ocasionó la pérdida de importancia de esta oficina administrativa.

La subida de los ingresos procedentes de las dehesas y de la recaudación de granos, y el estancamiento de las alcabalas, desplazó el centro de gravedad de las villas del Estado de Feria. A mediados de siglo Zafra 
era la villa más importante de todas para la hacienda ducal, pues contribuía con el 24,8 por 100 de todas las rentas, mientras que le seguian a una considerable distancia Santa Marta (con un 15,9 por 100) y Oliva (con un 15,8 por 100$)$. La reforma administrativa llevada a cabo en la década de los años 60, con la supresión de las mayordomias de Nogales y de Solana propició la recaudación en las de Santa Marta y Villalba de mayor contingentes de granos, y ello desplazó el centro de gravedad de Zafra hacia estas dos villas, de tal forma que en los nueve quinquenios estudiados Santa Marta superó a Zafra en cuatro ocasiones y Villalba en tres. Las tres dehesas ubicadas fuera del Estado de Feria adquirieron mayor relieve y evolucionaron del 10,5 por 100 de las rentas en el quinquenio 1765-70 al 21,1 por 100 en 1791-1795, superando en recaudación a todas las demás. La venta de dos de estas dehesas elevó a Oliva al primer lugar en el quinquenio de final de siglo con una participación del 21,3 por 100.

La positiva evolución de los ingresos de la hacienda ducal en la segunda mitad del siglo XVIII fue neutralizada en la etapa final del siglo por una inflación galopante de los precios del grano y no se tradujo en una mayor percepción de rentas liquidas por el Duque, pues los gastos y cargas se incrementaron en igual o mayor proporción, principalmente los réditos de censos.

A mediados del siglo xvill los gastos sumaban cifras próximas a los 150.000 reales, más de la mitad de los cuales eran pagos de réditos de 57 censos que se abonaban a obras religiosas y asistenciales. En la década de los años noventa las cargas se habian acrecentado de manera considerable, y los censos tenian hipotecada la economia del Estado de Feria, pues por sus réditos se pagaban 225.900 reales al año. El total de gastos en esos momentos debia situarse en unas cifras próximas a los 370.000 reales anuales, que se incrementaron imparablemente, y en los años finales de siglo se había llegado a cifras próximas al medio millón de reales. De esta importante canticiad, los censos absorbían 236.010 reales en 1800, y al año siguiente lo hacian de 258.504 reales. Con estos datos nos es posible afirmar que los réditos de censos habian hipotecado el porvenir de la hacienda del Estado de Feria en los albores del siglo Xix. Las rentas liquidas anuales en vez de aumentar disminuyeron a finales de siglo hasta unas cifras cercanas a los 150.000 reales. Para colmo de males, la coyuntura desfavorable para los pueblos del Estado impedia a los deudos del Duque cumplir sus compromisos. Por ello los concejos dejaban de pagar las alcabalas y los arrendadores de diezmos y de huertas se veian con grandes dificultades financieras. Las deudas con el Duque alcanzaban más de 300.000 reales en 1799, lo que supone que le debian en esos momentos el equivalente a dos años de ingresos liquidos. 
Únicamente los ganaderos trashumantes, arrendadores de la mayoría de las dehesas, pagaban puntualmente.

Las rentas totales percibidas por la casa ducal de Medinaceli de todos sus Estados no debieron ser suficientes para atender sus gastos, y el endeudamiento fue gigantesco. Como prueba de ello aparece el secuestro judicial de las rentas de sus Estados de Comares, Priego y Villalba en 1793, para pagar una deuda superior a tres millones de reales contraída con el conde de Goyeneche. Pero ésta era una pequeña muestra de las deudas de la Casa de Medinaceli, pues en 1797 se procedió a la venta de fincas de sus Estados por un juez comisionado por el Consejo de Castilla, para saldar una deuda de trece millones de reales. Se escogieron en el Estado de Feria dos dehesas situadas fuera del espacio jurisdiccional, consideradas como bienes "privados»; la de Monturque, Matilla y Marihernández en Jerez, que estaba arrendada a D. Francisco Pérez Caballero por 11.500 reales, y la del Redrojo en Rivera, que en esos momentos la aprovechaba D. Joaquín López Montenegro abonando 31.500 reales, ambos ganaderos transhumantes. 


\section{APÉNDICE}

Evolución de las rentas del estado de Feria en la segunda mitad del siglo xvill

(reales vn.)

\begin{tabular}{|c|c|c|c|c|c|c|c|c|c|}
\hline PUEBLOS Y RENTAS & $1751-541$ & $1761-651$ & $767-7011$ & $1771-751$ & $1776-801$ & $1781-851$ & $1786-90$ & $1791-95$ & $\begin{array}{l}1796- \\
1800\end{array}$ \\
\hline \multicolumn{10}{|l|}{ ZAFRA } \\
\hline Alcab. asientos paño ................... & 12.381 & 9.000 & 14.568 & 15.000 & 14.200 & 13.000 & 1.920 & 7.000 & 7.000 \\
\hline Alcab. as. curtiduria ..................... & 3.529 & 2.360 & 2.925 & 3.900 & 1.030 & 3.900 & 0 & 0 & 0 \\
\hline Alcab. as. zapateria ..................... & 2.491 & 1.380 & 1.464 & 1.820 & 1.612 & 1.950 & 1.342 & 971 & 878 \\
\hline Alcab. aceite y jabón ................. & 2.328 & 1.560 & 1.950 & 2.600 & 2.600 & 2.600 & 3.212 & 3.350 & 3.350 \\
\hline Alcab vino y vinagre .............. & 2.198 & 2.520 & 3.150 & 4.280 & 4.300 & 4.300 & 5.950 & 6.500 & 1,300 \\
\hline Alcab. carne y jarqu. ..... & 5.535 & 3.133 & 4.025 & 5.367 & 5.367 & 5.367 & 6.737 & 7.150 & 7.150 \\
\hline Alcab. bestiaje ................... & 2.002 & 1.478 & 1.581 & 1.873 & 1.620 & 1.500 & 1.525 & 1.600 & 2.530 \\
\hline Alcab. viento lencería ................. & 0 & 0 & 567 & 317 & 796 & 750 & 399 & 350 & 605 \\
\hline Alcab. azúcar y cacao ................ & 0 & 0 & 0 & 467 & 643 & 963 & 2.166 & 1.046 & 4.489 \\
\hline Alcab. molinos ............ & 0 & 112 & 0 & 0 & 146 & 0 & 11 & 162 & 73 \\
\hline 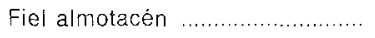 & 980 & 610 & 612 & 0 & 0 & 0 & 0 & 914 & 1.081 \\
\hline Alcab. feria S. Juan ....................... & 2.638 & 1.558 & 1.680 & 2.316 & 1.474 & 317 & 3.044 & 1.182 & 327 \\
\hline Alcab feria S. Miguel .................. & 4.119 & 4.419 & 3.423 & 6.145 & 7.610 & 10.850 & 11.597 & 12.610 & 14.415 \\
\hline Alcab. administradas ..................... & 33.926 & 21.130 & 36.981 & 26.962 & 29.045 & 30.285 & 28.615 & 28.997 & 35.108 \\
\hline Alcab padrón vecindar ............... & 0 & 1.200 & 0 & 0 & 1.338 & 6.458 & 6.603 & 6.286 & 6.173 \\
\hline 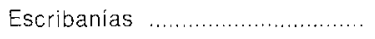 & 850 & 480 & 600 & 800 & 800 & 800 & 800 & 800 & 1.000 \\
\hline Peso de la harina ....................... & 0 & 0 & 0 & 0 & 440 & 1.299 & 1.464 & 612 & 638 \\
\hline Arriendo de casas & 0 & 0 & 0 & 0 & 165 & 220 & 323 & 163 & 0 \\
\hline Censo del cubo ................... & 0 & 0 & 0 & 0 & 0 & 1 & 4 & 4 & 4 \\
\hline 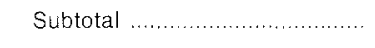 & 72.977 & 50.940 & 73.527 & 71.846 & 76.057 & 81.690 & 75.713 & 79.695 & 86.121 \\
\hline \multicolumn{10}{|l|}{ LA PARRA } \\
\hline 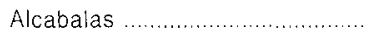 & 3.550 & 3.550 & 3.550 & 3.550 & 3.550 & 3.550 & 3.550 & 3.550 & 3.550 \\
\hline 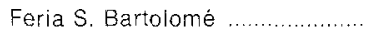 & 572 & 1.040 & 1.224 & 1.370 & 1.640 & 1.904 & 2.919 & 3.620 & 4.790 \\
\hline Dehesa de Salamanco ............... & 0 & 4.800 & 5.000 & 5.525 & 7.628 & 8.008 & 8.402 & 9.393 & 10.612 \\
\hline Bellota deh. Salam. ......................... & 0 & 492 & 745 & 1.562 & 2.020 & 2.019 & 2.031 & 3.406 & 5.469 \\
\hline Subtotal ....... & 4. 122 & 9.882 & 10.520 & 12.008 & 14.838 & 15.482 & 16.902 & 19.970 & 24.421 \\
\hline \multicolumn{10}{|l|}{ LA MORERA } \\
\hline Alcabalas & 1340 & 1.350 & 1.350 & 1.350 & 1.350 & 1.350 & 1.350 & 1.350 & 1.350 \\
\hline
\end{tabular}




\section{NOGALES}

Alcabalas y escribania Novenos de grano.....

Dehesa de Santa Juste

Dehesa de Santa Justa ..............

Dehesa Entrin Bajero ................

Rastrojos

Huerta Moreras

Censo molino harinero

Censo Valdelamorera

Subtotal

\section{SALVALEON}

Alcabalas y escribania...

Censo Monte Porrino

Dehesa de Palacio

Molinos y huertas

Dehesa Bejarana

Censo sobre solares

Subtotal

LA TORRE

Alcabalas y escribania

1.850

ALMENDRA:

Alcabalas y escribania

4.425

4.425

4.425

4.425

4. 425

3.385

5.475

4.425

4.425

ALCONERA

Alcabalas

600

912

920

920

920

920

920

920

920

\section{SALVATIERRA}

Escribania censo cercados

OLIVA DE LA FRONTERA

Dehesa del Campo

Diezmo de grano

13.000

2,080

2.080

$17.664 \quad 24.23$

16.075

23.744

2.068

2.02

2.065

1.664

2.020

Diezmo de lechones

$14.039 \quad 7.429$

4.485

26.150

56.501

$\begin{array}{lll}21.000 & 22.400 \quad 28.000\end{array}$

Diezmo de borregos

$0 \quad 2.502$

1.876

14.601

20.384

21.169

42.589

$12.589 \quad 53.320$

Arreala de serranos

$0 \quad 54$

$0 \quad 1.67$

1.844

1306

2.295

2.598

12.706

$7.688 \quad 38.327$

Diezmo de chivos ......................

Diezmo de lino, lana

$0 \quad 3.42$

2.583

2.758

2.885

1.526

2.115

$951 \quad 1.657$

Rebujales

Diezmo casas excusadas

Huerto Pomar

0

Censo dehesa Campil

Casa

$150 \quad 156$

$44 \quad 44$

$0 \quad 36$

5.138

5.167

4.371

0

0

0

119

4.980

5.928

$2.280 \quad 4.040$

$3.120 \quad 7.920$

200

0

2.236

2.316

363

$199 \quad 143$

220

250

372

3.285

$1.986 \quad 318$

$\begin{array}{rrr}44 & 44 & 44\end{array}$

59

192

59

296

Subtotal

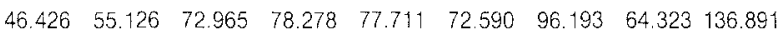


Las rentas del ducado de Feria en la segunda mitad del siglo xvIII

\begin{tabular}{|c|c|c|c|c|c|c|c|c|c|}
\hline PUEBLOS Y RENTAS & $1751-54$ & $1761-65$ & $1767-70$ & $1771-75$ & $1776-80$ & $1781-85$ & $1786-90$ & $1791-95$ & $\begin{array}{l}1796 \\
1800\end{array}$ \\
\hline \multicolumn{10}{|l|}{ VALENCłA DE MOMBUEY } \\
\hline Alcabalas y escribania ............... & 500 & 520 & 520 & 520 & 520 & 520 & 520 & 416 & 520 \\
\hline 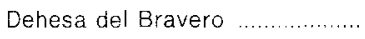 & 5.700 & 4.650 & 2.850 & 2.559 & 7.892 & 8.286 & 8.694 & 8.879 & 8.879 \\
\hline Censo dehesa Campillo ............. & 44 & 44 & 44 & 44 & 44 & 22 & 29 & 23 & 29 \\
\hline Subtotal & 6.244 & 5.124 & 3.414 & 3.123 & 8.456 & 8.828 & 9.243 & 9.318 & 9.428 \\
\hline \multicolumn{10}{|l|}{ VILLALBA } \\
\hline Alcabalas y escribanía ................ & 772 & 824 & 830 & 824 & 800 & 800 & 800 & 800 & 800 \\
\hline 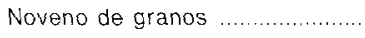 & 23.959 & 58.131 & 48.129 & 8.399 & 65.321 & 35.024 & 23.813 & 37.518 & 61.073 \\
\hline Noveno de ganados .................. & 9.949 & 16.712 & 12.320 & 8.547 & 11.086 & 12.094 & 9.487 & 12.650 & 14.325 \\
\hline 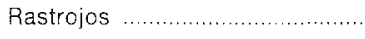 & 4.965 & 2.318 & 13.267 & 5.117 & 1.508 & 835 & 877 & 1.080 & 1.027 \\
\hline Subtotal & 39.645 & 77.985 & 75.546 & 22.888 & 78.715 & 48.753 & 34.977 & 52.048 & 77.225 \\
\hline
\end{tabular}

SANTA MARIA

Alcabalas y escribanía

$\begin{array}{lllllllll}1.674 & 1.678 & 1.678 & 1.678 & 1.678 & 1.678 & 1.678 & 1.678 & 1.678\end{array}$

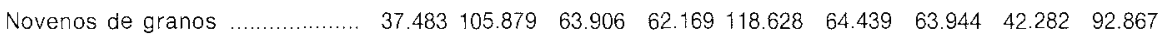

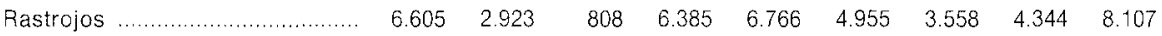

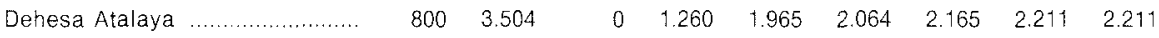

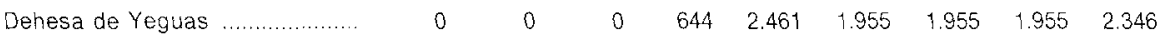

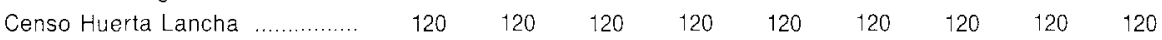

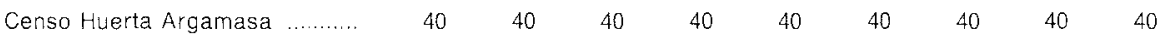

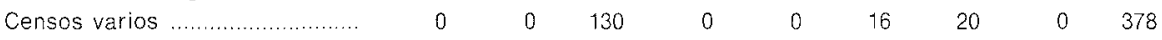

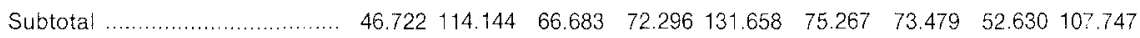

SOLANA

\begin{tabular}{|c|c|c|c|c|c|c|c|c|}
\hline Alcabalas & 480 & 480 & 480 & 480 & 480 & 480 & 480 & 388 \\
\hline Rastrojos & 1.414 & 14.390 & 201 & 1.441 & 1.435 & 912 & 1.045 & 703 \\
\hline Subtotal & 1.894 & 14.870 & 681 & 1.921 & 1.915 & 1.392 & 1.525 & 1.091 \\
\hline
\end{tabular}

CORTE DE PELEAS

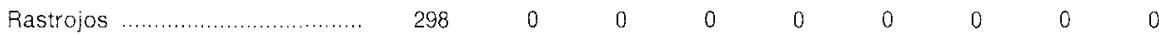
(Las alcabalas no se cobran por escasa población. 'os novenos y rastrojos en la cuenta de Sta. Marta). 


\section{OTRAS RENTAS}

MEDINA. Censo h. Argamasa ...

$\begin{array}{rrrrrrrrr}941 & 941 & 941 & 941 & 941 & 941 & 941 & 941 & 941 \\ 1.500 & 1.500 & 1.500 & 1.500 & 1.500 & 1.500 & 1.500 & 1.500 & 1.500 \\ 0 & 0 & 0 & 4.000 & 10.310 & 12.879 & 15.500 & 13.290 & 5.400 \\ 0 & 0 & 0 & 22.060 & 28.900 & 29.200 & 30.000 & 30.600 & 6.300\end{array}$

RIVERA. Dehesa Redrojo

CABEZA DEL BUEY

- Dehesa de Almorchón ..........

$\begin{array}{llllllllll}0 & 14.285 & 35.506 & 39.651 & 41.075 & 42.625 & 44.454 & 50.704 & 57.335\end{array}$

- Agostadero D. Almorchón ....

- Millar D. Almorchón

$\begin{array}{rrrrrrrrr}0 & 85 & 2.883 & 1.682 & 3.281 & 3.281 & 1.640 & 0 & 0 \\ 0 & 0 & 0 & 2.168 & 5.932 & 6.765 & 7.182 & 7.335 & 7.335\end{array}$

- Huerta D. Almorchón

TOTAL DE RENTAS DEL ESTA.

DO DE FERIA

Nota: Hemos insertado las rentas medias anuales de cada quinquenio.

Fuente: AHMZ, FDF, 0101. Cuentas Generales del Estado de Feria del periodo 1751 al 1800 C. 167, leg. 28, Rentas del Duque en 1773. C. 53, leg. 2, Rentas del Duque en 1794 C. 124 , leg. 16, Rentas para liq. contr. 1799. C. 141, leg. 1, Valores de hierbas, rastr. 1794-1798.

C. 93. leg. 45. Arr. dehesas a Montenegro. 1775-1795. 